\title{
Performance assessment of GPS receivers during the September 24, 2011 solar radio burst event
}

\author{
Bilal Muhammad ${ }^{1, *}$, Valentina Alberti ${ }^{2}$, Alessandro Marassi ${ }^{2}$, Ernestina Cianca ${ }^{1}$, and Mauro Messerotti ${ }^{2,3}$ \\ 1 Department of Electronic Engineering, University of Rome Tor Vergata, 00133 Rome, Italy \\ *Corresponding author: bilal@ing.uniroma2.it \\ 2 INAF-Astronomical Observatory of Trieste, 34149 Trieste, Italy \\ 3 Department of Physics, University of Trieste, 34127 Trieste, Italy
}

Received 17 March 2015 / Accepted 22 August 2015

\begin{abstract}
The sudden outburst of in-band solar radio noise from the Sun is recognized as one of the potential Radio Frequency Interference (RFI) sources that directly impact the performance of Global Navigation Satellite System (GNSS) receivers. On September 24, 2011, the solar active region 1302 unleashed a moderate M7.1 soft X-ray flare associated with a very powerful radio burst at $1415 \mathrm{MHz}$. The Solar Radio Burst (SRB) event spanned over three distinct episodes of solar radio noise emission that reached the maximum radio flux density of 114,144 Solar Flux Units (SFU) at 13:04:46 UTC. This paper analyzes the impact of September 24, 2011 SRB event on the performance of a significant subset of NAVSTAR Global Positioning System (GPS) receivers located in the sunlit hemisphere. The performance assessment is carried out in terms of Carrier-to-Noise power spectral density ratio $\left(C / N_{0}\right)$ degradation, dual-frequency pseudorange measurements availability, pseudorange residual errors, and dualfrequency positioning errors in the horizontal and vertical dimensions. We observed that during the SRB event the GPS $C / N_{0}$ is reduced at most by $13 \mathrm{~dB}$ on $\mathrm{L} 1$ and $24 \mathrm{~dB}$ on L2. The $C / N_{0}$ degradation caused the loss of lock on GPS L1 and L2 signals and significant code-tracking errors. We noticed that many stations experienced less than four satellite measurements, which are the minimum required number of measurements for position estimation. The deteriorated satellite-receiver geometry due to loss of signal lock and significant code-tracking errors during the solar radio burst event introduced large positioning errors in both the horizontal and vertical dimensions. Rise in vertical positioning error of $303 \mathrm{~m}$ and rise in horizontal positioning of $55 \mathrm{~m}$ could be noticed during the solar radio burst event.
\end{abstract}

Key words. Radio Flux - Positioning System - Flares

\section{Introduction}

NAVSTAR GPS is a Global Navigation Satellite System (GNSS) widely in use for Positioning, Navigation, and Timing (PNT). GPS satellite transmits Right Hand Circularly Polarized (RHCP) L-band signals at the frequencies known as L1 (1575.24 MHz) and L2 (1227.60 MHz) (GPS ICD 2012). The minimum user-received power at unity gain $(0 \mathrm{dBic}) \mathrm{RHCP}$ antenna is $-158.1 \mathrm{dBW}$ for $\mathrm{L} 1 \mathrm{C} / \mathrm{A}$ and $-163.1 \mathrm{dBW}$ for L2 P(Y) (Ward et al. 2005a), and the corresponding power spectral densities are $-221.21 \mathrm{dBW} \mathrm{Hz}^{-1}$ and $-236.21 \mathrm{dBW} \mathrm{Hz}^{-1}$ for L1 C/A and L2 respectively. Assuming an equivalent noise temperature $T_{\text {eq }}=513 \mathrm{~K}$, the GPS receiver noise power spectral density $N_{0}=k \times T_{\mathrm{eq}}=-201.5 \mathrm{dBW} \mathrm{Hz}^{-1}$ (Klobuchar et al. 1999). The comparison of GPS L1 C/A and L2 power spectral densities with their respective noise power spectral densities indicates that the user-received L1 C/A signal power is approximately $20 \mathrm{~dB}$ lower than the noise power, whereas the user-received L2 signal power is $35 \mathrm{~dB}$ lower than the GPS receiver thermal noise power. The extremely low received power levels of these signals make them vulnerable to in-band radio frequency interference. The encrypted GPS L2 signal is of particular concern since it is much more susceptible to RFI than L1 due to the signal tracking using codeless/ semi-codeless technologies employed by dual-frequency GPS receivers.
A solar radio burst is the sudden outburst of radio noise from the Sun, which decreases $C / N_{0}$ of every tracked satellite signal by increasing the noise floor of GNSS receiver (Klobuchar et al. 1999). The degradation in $C / N_{0}$ due to the wideband solar radio frequency interference can result in degraded navigation accuracy or complete loss of receiver tracking. This could be an issue for a wide range of applications that demand uninterrupted satellite navigation service with a certain level of accuracy, particularly for the Safety of Life (SoL) applications relying on the use of GNSS, for instance, aircraft landing procedures in civil aviation.

Klobuchar et al. (1999) were the first to report the potential impact of solar radio bursts on GPS signal $C / N_{0}$. According to Klobuchar et al. (1999), the RHCP SRB flux required to just equal the GPS receiver thermal noise is 20,000 SFU $\left(1 \mathrm{SFU}=10^{-22} \mathrm{Wm}^{-2} \mathrm{~Hz}^{-1}\right)$. Considering an antenna gain of $1 \mathrm{~dB}$, an equivalent noise temperature of $513 \mathrm{~K}$, and an effective antenna area $\left(A_{\mathrm{e}}\right)$ of $24.4 \mathrm{~dB}$, a solar radio burst of 20,000 SFU would cause $3 \mathrm{~dB}$ drop on L1 $C / N_{0}$ as computed using the expression derived in Kennewell (1989) solar that is given by:

$$
\frac{\Delta C}{N_{0}}=10 \times \log \left(1+\frac{\mathrm{SRB} \times A_{\mathrm{e}}}{k \times T_{\mathrm{eq}}}\right),
$$

where $\frac{\Delta C}{N_{0}}$ is the degradation in $C / N_{0}$ caused by the SRB flux. For most GPS receivers, $3 \mathrm{~dB}$ drop on L1 $C / N_{0}$ might not be 


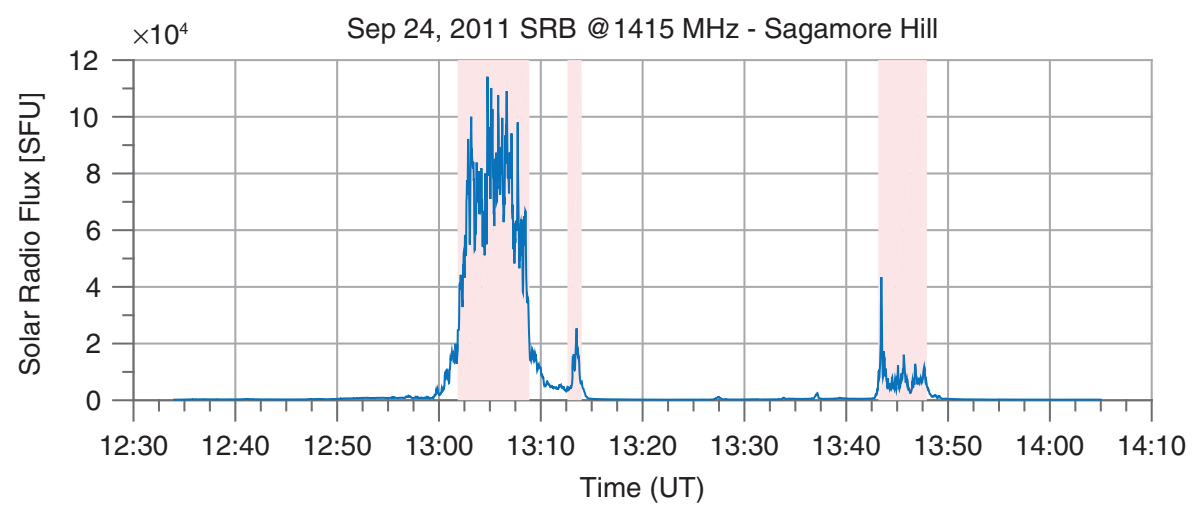

Fig. 1. September 24, 2011 solar radio flux recorded at $1415 \mathrm{MHz}$ at Sagamore Hill, USA. The solar radio burst episodes are highlighted in pink color.

Table 1. September 24, 2011 Solar radio noise flux recorded at $1415 \mathrm{MHz}$ at Sagamore Hill, USA.

\begin{tabular}{|c|c|c|c|c|c|c|}
\hline \multirow[t]{2}{*}{ Observatory } & \multicolumn{2}{|c|}{ Episode 1} & \multicolumn{2}{|c|}{ Episode 2} & \multicolumn{2}{|c|}{ Episode 3} \\
\hline & Peak flux [SFU] & Peak time & Peak flux [SFU] & Peak time & Peak flux [SFU] & Peak time \\
\hline Sagamore & 114,144 & $13: 04: 46$ & 25,377 & $13: 13: 31$ & 43,417 & $13: 43: 27$ \\
\hline
\end{tabular}

of concern (Klobuchar et al. 1999), however, $C / N_{0}$ degradation beyond a certain threshold would cause the loss of lock of GPS signals. Chen et al. (2005) evaluation derived the solar radio noise thresholds that can potentially cause loss of lock on GPS L2, which is about $2 \times 10^{4}$ to $1 \times 10^{5} \mathrm{SFU}$ for semi-codeless receivers, whereas for codeless receiver the threshold is about $1 \times 10^{3}$ to $8 \times 10^{3}$ SFU. These thresholds may tend to vary for different types of receivers.

The first ever quantitative measurements of GPS L1/L2 and Wide Area Augementation System (WAAS) $C / N_{0}$ degradation due to solar radio bursts were made by Cerruti et al. (2006) observed. From the perspective of the GPS user, what matters most is the rise in positioning error introduced by the solar radio noise during the solar radio burst event. Carrano et al. (2009) impacts analyzed the impact of December 2006 solar radio burst on the performance of GPS positioning in addition to $\left(C / N_{0}\right)$ degradation: more precisely, the authors showed that the depth of GPS signal fading due to solar radio burst is related to local solar incidence angle and the gain of GNSS antenna at the solar incidence angle (Sreeja et al. 2013, 2014) analyzed the impact of September 24, 2011 radio burst on GPS $C / N_{0}$ and Precise Point Positioning (PPP) service.

The in-band solar radio noise impacts all the satellites visible to the GNSS receiver located in the sunlit hemisphere. The signal loss of lock due to the solar RFI degrades the quality of the estimated position solution since it reduces the number of available satellites measurements to estimate the position. The reported studies that analyzed the impact of solar radio burst events on the performance of GPS receiver positioning highlighted that the deteriorated satellite-receiver geometry due to signal loss of lock raises the positioning errors. However, the reported works did not discuss the impact on the quality of the position solution of the satellites that are locked by the GPS receiver with degraded $C / N_{0}$. The locked satellites with degraded $C / N_{0}$ introduce significant tracking errors that could further degrade the quality of the estimated position solution.

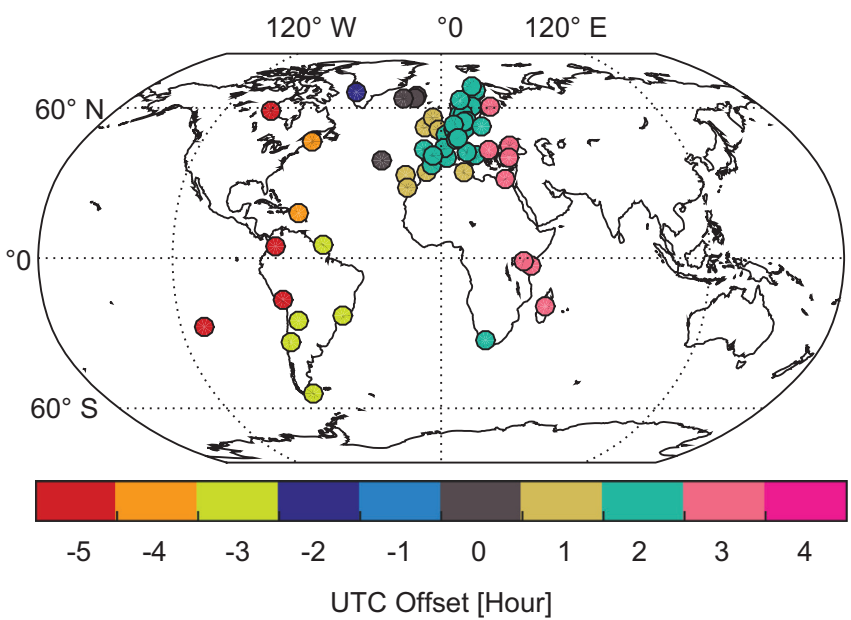

Fig. 2. The circles represent the geographic locations of GPS receiver stations considered in this study.

The quality of the GPS position solution is a function of satellite-receiver geometry and pseudorange measurement error (Parkinson 1996):

$$
\sigma_{\mathrm{pos}}=\mathrm{GDOP} \times \sigma_{\mathrm{PR}},
$$

where $\sigma_{\text {pos }}$ is the predicted or expected accuracy of the navigation position solution and GDOP stands for the Geometric Dilution of Precision. The GDOP is purely a function of satellite-receiver geometry, which is the Root Sum Square (RSS) of Horizontal Dilution of Precision (HDOP), Vertical Dilution of Precision (VDOP), and Time Diluton of Precision (TDOP). The HDOP and VDOP are computed as follows:

$$
\begin{aligned}
Q & =\left(G^{T} \times G\right)^{-1} \\
\mathrm{HDOP} & =\sqrt{Q_{1,1}+Q_{2,2}}, \\
\mathrm{VDOP} & =\sqrt{Q_{3,3}}
\end{aligned}
$$


B. Muhammad et al.: Performance of GPS receivers during Sep. 24, 2011 solar radio burst event

Table 2. Location, receiver, and antenna information of GPS stations. Each station is represented by unique four character station ID.

\begin{tabular}{|c|c|c|c|c|c|c|c|}
\hline \multirow[t]{2}{*}{ Station } & \multicolumn{3}{|c|}{ Location } & \multirow{2}{*}{$\begin{array}{l}\text { UTC } \\
\text { offset }\end{array}$} & \multirow[t]{2}{*}{ Receiver } & \multirow[t]{2}{*}{ Antenna } & \multirow[t]{2}{*}{ Agency } \\
\hline & Latitude & Longitude & Country & & & & \\
\hline $\mathrm{ABPO}$ & $19.02^{\circ} \mathrm{S}$ & $47.23^{\circ} \mathrm{E}$ & Antananarivo, Madagascar & 3.00 & ASHTECH UZ-12 & ASH701945G_M & IGS \\
\hline ACRA & $38.52^{\circ} \mathrm{N}$ & $28.62^{\circ} \mathrm{W}$ & Azores Islands, Portugal & 0.00 & BI-FREQUENCY & N/A & EGNOS \\
\hline ALBA & $57.1^{\circ} \mathrm{N}$ & $9.883^{\circ} \mathrm{E}$ & Aalborg, Denmark & 2.00 & BI-FREQUENCY & $\mathrm{N} / \mathrm{A}$ & EGNOS \\
\hline ALYA & $31.18^{\circ} \mathrm{N}$ & $29.96^{\circ} \mathrm{E}$ & Alexandria, Egypt & 3.00 & BI-FREQUENCY & $\mathrm{N} / \mathrm{A}$ & EGNOS \\
\hline AREQ & $16.47^{\circ} \mathrm{S}$ & $71.49^{\circ} \mathrm{W}$ & Arequipa, Peru & -5.00 & ASHTECH UZ-12 & $\mathrm{AOAD} / \mathrm{M}_{-} \mathrm{T}$ & IGS \\
\hline BOGT & $4.64^{\circ} \mathrm{N}$ & $74.08^{\circ} \mathrm{W}$ & Bogota, Columbia & -5.00 & ASHTECH UZ-12 & ASH701945E_M & IGS \\
\hline BRNA & $52.36^{\circ} \mathrm{N}$ & $13.54^{\circ} \mathrm{E}$ & Berlin, Germany & 2.00 & BI-FREQUENCY & N/A & EGNOS \\
\hline CHPI & $22.69^{\circ} \mathrm{S}$ & $44.99^{\circ} \mathrm{W}$ & $\begin{array}{c}\text { Cachoeira Paulista, Sao } \\
\text { Paulo, Brazil }\end{array}$ & -3.00 & ASHTECH UZ-12 & ASH701945C_M & IGS \\
\hline CHUR & $58.76^{\circ} \mathrm{N}$ & $94.09^{\circ} \mathrm{W}$ & Churchill, Canada & -5.00 & TPS NET-G3A & ASH701945E_M & IGS \\
\hline CRAO & $44.41^{\circ} \mathrm{N}$ & $33.99^{\circ} \mathrm{E}$ & Simeiz, Ukraine & 3.00 & ASHTECH UZ-12 & ASH701945C_M & IGS \\
\hline CRKA & $51.84^{\circ} \mathrm{N}$ & $8.496^{\circ} \mathrm{W}$ & Cork, Ireland & 1.00 & BI-FREQUENCY & $\mathrm{N} / \mathrm{A}$ & EGNOS \\
\hline CRO1 & $17.76^{\circ} \mathrm{N}$ & $64.58^{\circ} \mathrm{W}$ & $\begin{array}{l}\text { Christiansted, Virgin } \\
\text { Islands, US }\end{array}$ & -4.00 & ASHTECH UZ-12 & ASH701945G_M & IGS \\
\hline DJAA & $33.88^{\circ} \mathrm{N}$ & $10.77^{\circ} \mathrm{E}$ & Djerba, Tunis & 1.00 & BI-FREQUENCY & $\mathrm{N} / \mathrm{A}$ & EGNOS \\
\hline EBRE & $40.82^{\circ} \mathrm{N}$ & $0.4923^{\circ} \mathrm{E}$ & Ebro, Spain & 2.00 & TRIMBLE NETRS & TRM29659.00 & IGS \\
\hline EGIA & $65.28^{\circ} \mathrm{N}$ & $14.4^{\circ} \mathrm{W}$ & Egilsstaoir, Iceland & 0.00 & BI-FREQUENCY & N/A & EGNOS \\
\hline FFMJ & $50.09^{\circ} \mathrm{N}$ & $8.665^{\circ} \mathrm{E}$ & Frankfurt, Germany & 2.00 & JPS LEGACY & LEIAR25.R4 & IGS \\
\hline GLGA & $55.87^{\circ} \mathrm{N}$ & $4.446^{\circ} \mathrm{W}$ & Glasgow, UK & 1.00 & BI-FREQUENCY & $\mathrm{N} / \mathrm{A}$ & EGNOS \\
\hline GOLA & $39.64^{\circ} \mathrm{N}$ & $32.8^{\circ} \mathrm{E}$ & Konya, Turkey & 3.00 & BI-FREQUENCY & $\mathrm{N} / \mathrm{A}$ & EGNOS \\
\hline GVLA & $60.67^{\circ} \mathrm{N}$ & $17.13^{\circ} \mathrm{E}$ & Gavle, Sweden & 2.00 & BI-FREQUENCY & N/A & EGNOS \\
\hline HOFN & $64.27^{\circ} \mathrm{N}$ & $15.2^{\circ} \mathrm{W}$ & Hofn, Iceland & 0.00 & TPS E_GGD & TPSCR3_GGD & IGS \\
\hline HUEG & $47.83^{\circ} \mathrm{N}$ & $7.596^{\circ} \mathrm{E}$ & Huegelheim, Germany & 2.00 & JPS LEGACY & TPSCR3_GGD & IGS \\
\hline ISPA & $27.12^{\circ} \mathrm{S}$ & $109.3^{\circ} \mathrm{W}$ & Easter Island, Chile & -5.00 & ASHTECH UZ-12 & ASH701945E_M & IGS \\
\hline KELY & $66.99^{\circ} \mathrm{N}$ & $50.94^{\circ} \mathrm{W}$ & Kangerlussuaq, Greenland & -2.00 & ASHTECH UZ-12 & ASH701945C_M & IGS \\
\hline KIRU & $67.86^{\circ} \mathrm{N}$ & $20.97^{\circ} \mathrm{E}$ & Kiruna, Sweden & 2.00 & ASHTECH UZ-12 & ASH701945C_M & IGS \\
\hline KOUR & $5.252^{\circ} \mathrm{N}$ & $52.81^{\circ} \mathrm{W}$ & Kourou, French Guiana & -3.00 & JPS LEGACY & ASH701946.3 & IGS \\
\hline LAPA & $60.54^{\circ} \mathrm{N}$ & $27.56^{\circ} \mathrm{E}$ & Lappeenranta, Finland & 3.00 & BI-FREQUENCY & N/A & EGNOS \\
\hline LEIJ & $51.35^{\circ} \mathrm{N}$ & $12.37^{\circ} \mathrm{E}$ & Leipzig, Germany & 2.00 & JPS LEGACY & LEIAR25.R3 & IGS \\
\hline MAD2 & $40.43^{\circ} \mathrm{N}$ & $4.25^{\circ} \mathrm{W}$ & Madrid, Spain & 2.00 & ASHTECH Z-XII3T & AOAD/M_T & IGS \\
\hline MADA & $32.75^{\circ} \mathrm{N}$ & $16.71^{\circ} \mathrm{W}$ & Madeira, Portugal & 2.00 & BI-FREQUENCY & $\mathrm{N} / \mathrm{A}$ & EGNOS \\
\hline MADR & $40.43^{\circ} \mathrm{N}$ & $4.25^{\circ} \mathrm{W}$ & Madrid, Spain & 2.00 & ASHTECH Z-XII3 & AOAD/M_T & IGS \\
\hline MAL2 & $2.996^{\circ} \mathrm{S}$ & $40.19^{\circ} \mathrm{E}$ & Malindi, Kenya & 3.00 & JPS LEGACY & ASH701945C_M & IGS \\
\hline MLGA & $36.68^{\circ} \mathrm{N}$ & $4.514^{\circ} \mathrm{W}$ & Malaga, Spain & 2.00 & BI-FREQUENCY & N/A & EGNOS \\
\hline MAR6 & $60.6^{\circ} \mathrm{N}$ & $17.26^{\circ} \mathrm{E}$ & Maarstbo, Sweden & 2.00 & JPS E_GGD & AOAD/M_T & IGS \\
\hline MAS1 & $27.76^{\circ} \mathrm{N}$ & $15.63^{\circ} \mathrm{W}$ & $\begin{array}{l}\text { Maspalomas, Canary } \\
\text { Islands, Spain }\end{array}$ & 1.00 & JPS LEGACY & ASH701945E_M & IGS \\
\hline MATE & $40.65^{\circ} \mathrm{N}$ & $16.7^{\circ} \mathrm{E}$ & Matera, Italy & 2.00 & LEICA GRX1200GG & LEIAT504GG & IGS \\
\hline MONA & $46.07^{\circ} \mathrm{N}$ & $64.77^{\circ} \mathrm{W}$ & Ottawa, Canada & -4.00 & BI-FREQUENCY & N/A & EGNOS \\
\hline ONSA & $57.4^{\circ} \mathrm{N}$ & $11.93^{\circ} \mathrm{E}$ & Onsala, Sweden & 2.00 & JPS E_GGD & AOAD/M_B & IGS \\
\hline PARA & $48.84^{\circ} \mathrm{N}$ & $2.335^{\circ} \mathrm{E}$ & Paris, France & 2.00 & BI-FREQUENCY & $\mathrm{N} / \mathrm{A}$ & EGNOS \\
\hline PDMA & $39.56^{\circ} \mathrm{N}$ & $2.739^{\circ} \mathrm{E}$ & Palma De Mallorca, Spain & 2.00 & BI-FREQUENCY & $\mathrm{N} / \mathrm{A}$ & EGNOS \\
\hline RABT & $34^{\circ} \mathrm{N}$ & $6.854^{\circ} \mathrm{W}$ & Rabat, Morocco & 1.00 & ASHTECH UZ-12 & TRM29659.00 & IGS \\
\hline $\mathrm{RCMN}$ & $1.221^{\circ} \mathrm{S}$ & $36.89^{\circ} \mathrm{E}$ & Nairobi, Kenya & 3.00 & LEICA GRX1200GG & LEIAT504GG & IGS \\
\hline $\mathrm{RIO} 2$ & $53.79^{\circ} \mathrm{S}$ & $67.75^{\circ} \mathrm{W}$ & Rio Grande, Argentina & -3.00 & ASHTECH Z-XII3 & ASH700936C_M & IGS \\
\hline RKKA & $64.13^{\circ} \mathrm{N}$ & $21.93^{\circ} \mathrm{W}$ & Reykjavik, Iceland & 0.00 & BI-FREQUENCY & N/A & EGNOS \\
\hline ROMA & $41.8^{\circ} \mathrm{N}$ & $12.58^{\circ} \mathrm{E}$ & Rome, Italy & 2.00 & BI-FREQUENCY & $\mathrm{N} / \mathrm{A}$ & EGNOS \\
\hline SANT & $33.15^{\circ} \mathrm{S}$ & $70.67^{\circ} \mathrm{W}$ & Santiago, Chile & -3.00 & ASHTECH UZ-12 & AOAD/M_T & IGS \\
\hline SASS & $54.51^{\circ} \mathrm{N}$ & $13.64^{\circ} \mathrm{E}$ & Sassnitz, Germany & 2.00 & JPS LEGACY & TPSCR3_GGD & IGS \\
\hline SDCA & $42.93^{\circ} \mathrm{N}$ & $8.425^{\circ} \mathrm{W}$ & $\begin{array}{c}\text { Santiago De Compostela, A } \\
\text { Coruna, Spain }\end{array}$ & 2.00 & BI-FREQUENCY & $\mathrm{N} / \overline{\mathrm{A}}$ & EGNOS \\
\hline SOFA & $42.68^{\circ} \mathrm{N}$ & $23.41^{\circ} \mathrm{E}$ & Sofia, Bulgaria & 3.00 & BI-FREQUENCY & $\mathrm{N} / \mathrm{A}$ & EGNOS \\
\hline SUTH & $32.38^{\circ} \mathrm{S}$ & $20.81^{\circ} \mathrm{E}$ & $\begin{array}{c}\text { Sutherland, Northern Cape, } \\
\text { South Africa }\end{array}$ & 2.00 & ASHTECH UZ-12 & ASH701945G_M & IGS \\
\hline SWAA & $50.89^{\circ} \mathrm{N}$ & $1.287^{\circ} \mathrm{W}$ & Gatwick, London, UK & 1.00 & BI-FREQUENCY & N/A & EGNOS \\
\hline TITZ & $51.04^{\circ} \mathrm{N}$ & $6.432^{\circ} \mathrm{E}$ & Titz, Germany & 2.00 & JPS LEGACY & LEIAR25.R4 & IGS \\
\hline TLSA & $43.43^{\circ} \mathrm{N}$ & $1.497^{\circ} \mathrm{E}$ & Toulouse, France & 2.00 & BI-FREQUENCY & N/A & EGNOS \\
\hline TRDA & $63.46^{\circ} \mathrm{N}$ & $10.9^{\circ} \mathrm{E}$ & Trondheim, Norway & 2.00 & BI-FREQUENCY & N/A & EGNOS \\
\hline TROA & $69.66^{\circ} \mathrm{N}$ & $18.94^{\circ} \mathrm{E}$ & Tromsø, Norway & 2.00 & BI-FREQUENCY & N/A & EGNOS \\
\hline UNSA & $24.73^{\circ} \mathrm{S}$ & $65.41^{\circ} \mathrm{W}$ & Salta, Argentina & -3.00 & SEPT POLARX2 & TPSCR3_GGD & IGS \\
\hline VILL & $40.44^{\circ} \mathrm{N}$ & $3.952^{\circ} \mathrm{W}$ & Villafranca, Spain & 2.00 & ASHTECH UZ-12 & AOAD/M_T & IGS \\
\hline WARN & $54.17^{\circ} \mathrm{N}$ & $12.1^{\circ} \mathrm{E}$ & $\begin{array}{c}\text { Rostock-Warnemuende, } \\
\text { Germany }\end{array}$ & 2.00 & JPS LEGACY & LEIAR25.R3 & IGS \\
\hline
\end{tabular}


Table 2. Continued.

\begin{tabular}{|c|c|c|c|c|c|c|c|}
\hline \multirow[t]{2}{*}{ Station } & \multicolumn{3}{|c|}{ Location } & \multirow{2}{*}{$\begin{array}{l}\text { UTC } \\
\text { offset }\end{array}$} & \multirow[t]{2}{*}{ Receiver } & \multirow[t]{2}{*}{ Antenna } & \multirow[t]{2}{*}{ Agency } \\
\hline & Latitude & Longitude & Country & & & & \\
\hline WRSA & $52.21^{\circ} \mathrm{N}$ & $21.07^{\circ} \mathrm{E}$ & Warsaw, Poland & 2.00 & BI-FREQUENCY & $\mathrm{N} / \mathrm{A}$ & EGNOS \\
\hline WSRT & $52.91^{\circ} \mathrm{N}$ & $6.605^{\circ} \mathrm{E}$ & $\begin{array}{l}\text { Westerbork, } \\
\text { Netherlands }\end{array}$ & 2.00 & AOA SNR-12 ACT & AOAD/M_T & IGS \\
\hline ZIM2 & $46.88^{\circ} \mathrm{N}$ & $7.465^{\circ} \mathrm{E}$ & $\begin{array}{l}\text { Zimmerwald, } \\
\text { Switzerland }\end{array}$ & 2.00 & TRIMBLE NETR5 & TRM59800.00 & IGS \\
\hline ZURA & $47.45^{\circ} \mathrm{N}$ & $8.565^{\circ} \mathrm{E}$ & Zurich, Switzerland & 2.00 & BI-FREQUENCY & $\mathrm{N} / \mathrm{A}$ & EGNOS \\
\hline
\end{tabular}

where $G$ is the $n \times 4$ geometry matrix such that its $i$ th row is defined as follows:

$$
G_{i}=\left[-\cos E l_{i} \sin A z_{i}-\cos E l_{i} \cos A z_{i}-\sin E l_{i} 1\right],
$$

where $E l_{i}$ is the elevation angle and $A z_{i}$ is the azimuth angle of the $i$ th satellite in view. Generally, the more satellites used in estimating the position solution, the smaller the HDOP/ VDOP values and hence the smaller the position solution error (Langley 1999). $\sigma_{\mathrm{PR}}$ is the pseudorange residual error that includes the contribution from all the error sources affecting the pseudorange measurement including the codetracking error of the Delay Lock Loop (DLL). The DLL produces the pseudorange measurements by aligning the local replica of the transmitted PRN Code with the incoming signal (Ward et al. 2005b). A simplified relationship of the $C / N_{0}$ and the standard deviation of the code-tracking errors of the DLL is provided in Spilker (1996) as:

$$
\sigma_{\mathrm{DLL}}=T_{c} \times \sqrt{\frac{B_{L}}{\frac{C}{N_{0}}}} \times c,
$$

where $\sigma_{\mathrm{DLL}}$ is the standard deviation of code-tracking errors in meters, $B_{\mathrm{L}}$ is the DLL noise bandwidth, $c$ is the speed of light, and $T_{c}$ is the chip period. Equation (5) indicates that degradation in $C / N_{0}$ increases the code-tracking errors, which degrades the quality of pseudorange measurements that eventually degrades the quality of the estimated position solution. From Eq. (2) it is evident that the key factors contributing to the quality of the GPS position solution are strongly affected by the solar radio burst, which eventually introduce large positioning errors.

This paper presents the adverse effect of September 24 solar radio burst on GPS dual-frequency standard point positioning and $C / N_{0}$ degradation on GPS L1 and L2 signals. The impact of September 24, 2011 radio burst on GPS $C / N_{0}$ is analyzed by Sreeja et al. (2013). While analyzing the impact on $C / N_{0}$, Sreeja et al. (2013) observed the GPS receiver $C / N_{0}$ recorded every $60 \mathrm{~s}$, which is a very low sampling rate that actually missed the key observation epochs where the solar radio burst caused deep fades in $C / N_{0}$. Moreover, the reported work analyzed the impact considering the peak solar radio burst, whereas the September 24, 2011 solar radio burst spanned over three different episodes of solar radio noise emission. In this study we present the impact of solar radio burst on GPS L1 and L2 signals observing $C / N_{0}$ sampled every second collected by 61 GPS receiver stations. This high sampling rate provides more accurate information of the signal fading due to September 24 solar radio burst event. Furthermore, we analyze the impact on dual-frequency GPS positioning performance by quantifying the rise in horizontal and vertical positioning errors due to deteriorated satellite-receiver geometry and codetracking errors caused by signal fading during each episode of September 24, 2011 solar radio burst event. The paper is organized as follows. Section 2 provides the details about the September 24, 2011 solar radio burst and observation data collected from GPS stations located in the sunlit hemisphere. Section 3 presents results with detailed analysis taking into account the degradation in $C / N_{0}$, dual-frequency measurements availability, pseudorange residual errors, and rise in horizontal and vertical positioning errors. The concluding remarks are provided in Section 4.

\section{Related work and pseudorange processing}

As mentioned in previous Section, Sreeja et al. (2013) conducted a similar study that analyzes the performance of GPS positioning during the solar radio burst event of September 24, 2011. GPS positioning results that are presented in this article are different in terms of positioning accuracy compared to the results published in Sreeja et al. (2013). For the sake of reader commodity, we would like to highlight possible reasons that led to the differences between positioning accuracies.

The major difference between the positioning accuracy is caused by the processing of pseudorange observations and error correction models used during the position estimation. It has to be remarked that the quality of position estimate is strongly related to: (1) pseudorange observation, (2) pseudorange error correction model, and (3) adjustment procedure (Sreeja et al. 2013) applied Precise Point Positioning (PPP) error correction models on dual-frequency code and carrierphase measurements using EHP/PPP software developed by Fugro Intersite, whereas in this study, we applied standard error correction models on dual-frequency code observations only using open-source standard point positioning goGPS (Herrera et al. 2015) software. It is worth mentioning that current version of goGPS supports single-frequency ionospheric correction, for this study we extended goGPS functionality by adding code-based dual-frequency ionospheric correction method using the method explained in Conley et al. (2005).

A brief overview of PPP models is provided in Kouba (2009), while for in-depth understanding of PPP technique the interested readers should refer to Marreiros (2012). The outlining difference between our study and the study conducted by Sreeja et al. (2013) is that they presented the impact of solar radio burst on the performance of PPP users, whereas we show how solar radio burst impacts the dual-frequency standard point positioning users, keeping in view that not all dualfrequency users are subscribed to PPP service. This work would facilitate the reader to analyze the impact of solar radio burst on dual-frequency positioning receivers that do not use PPP technique, thus allowing the readers to compare how different positioning techniques would perform during solar radio burst event. 


\section{Episode 1}
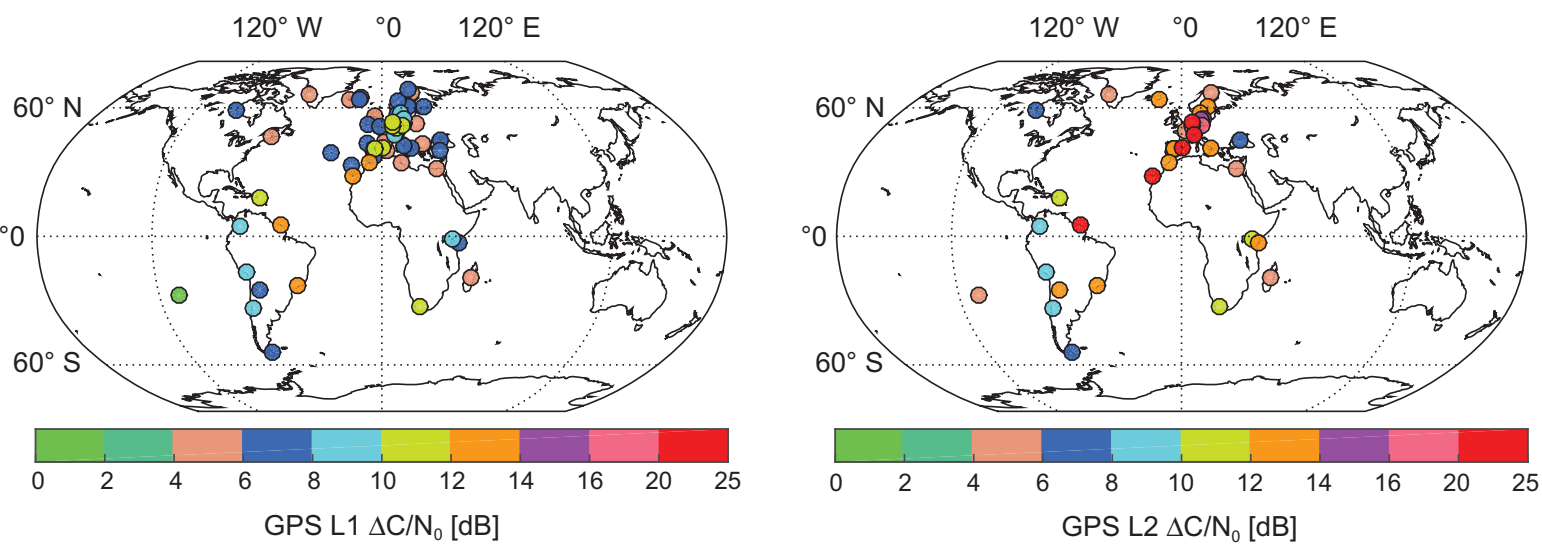

\section{Episode 2}
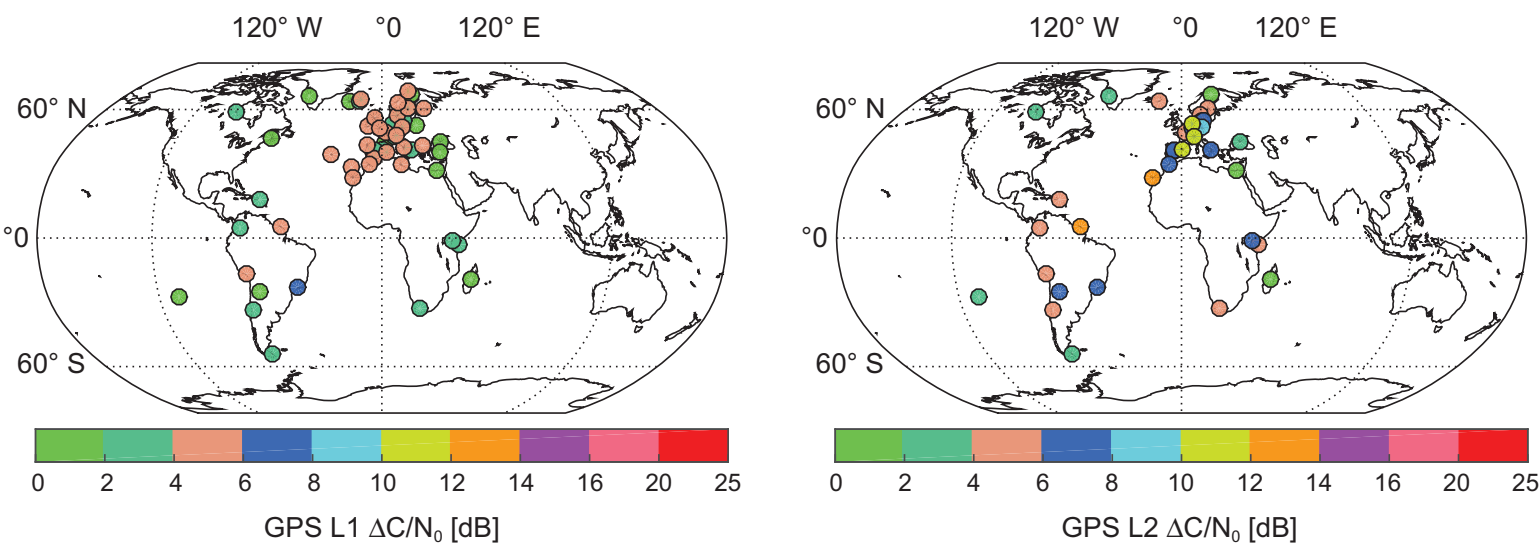

Episode 3
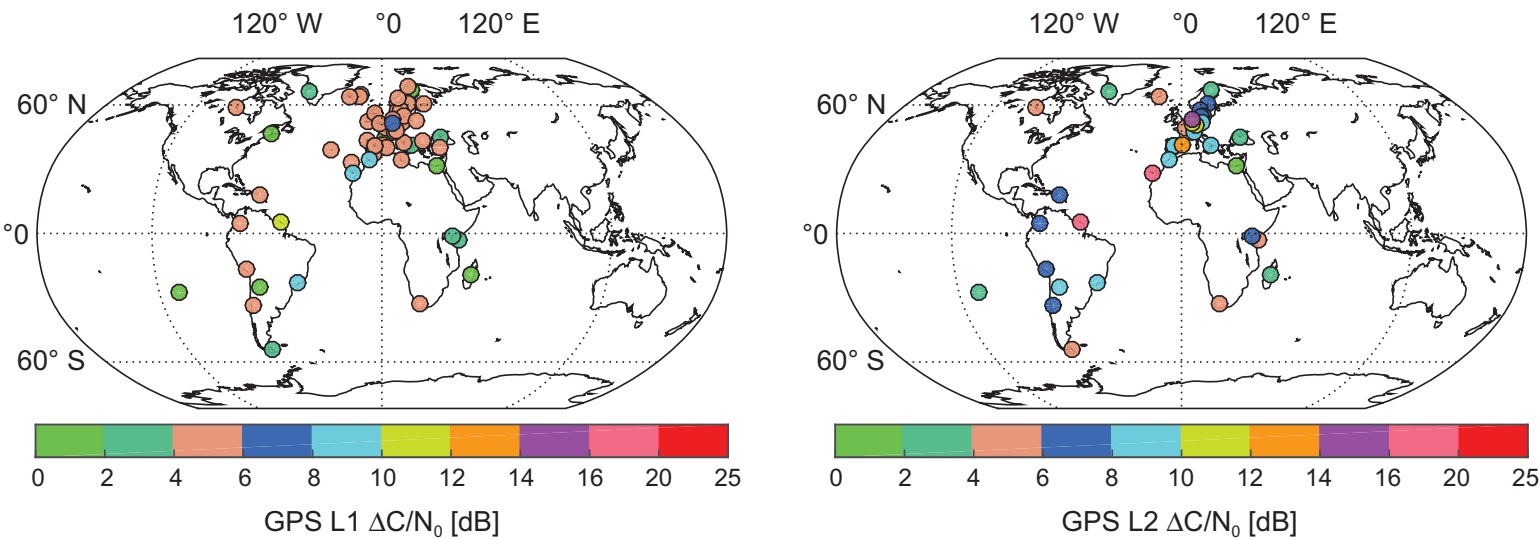

Fig. 3. GPS L1 and L2 $\Delta C / N_{0}$ during the September 24, 2011 solar radio burst. L2 $C / N_{0}$ values of EGNOS RIMS stations could not be found in RINEX files.

\section{Data description}

On September 24, 2011 the solar active region 1302 unleashed a moderate M7.1 soft X-ray flare associated with a very powerful radio burst at $1415 \mathrm{MHz}$. The solar radio burst started approximately at 12:34 and reached its maximum emission at 13:04 UTC when the radio flux density was as high as $110,000 \mathrm{SFU}$ at $1415 \mathrm{MHz}$ as reported by NOAA/SWPC (National Oceanic and Atmospheric Administration Space
Weather Prediction Center) daily solar event report available from the National Geophysical Data Center (NGDC) ftp:// ngdc.noaa.gov/STP/swpc_products/daily_reports/solar_event_ reports/2011/09/20110924events.txt. The evolution of the solar radio burst has been studied using one-second flux data obtained by the RSTN (Radio Solar Telescope Network) station situated at Sagamore Hill (USA). Before the end of the event at 14:05 UTC, other two peaks in the radio flux reached values higher than $1 \times 10^{4}$ SFU as shown in Figure 1 . The timing and peak 

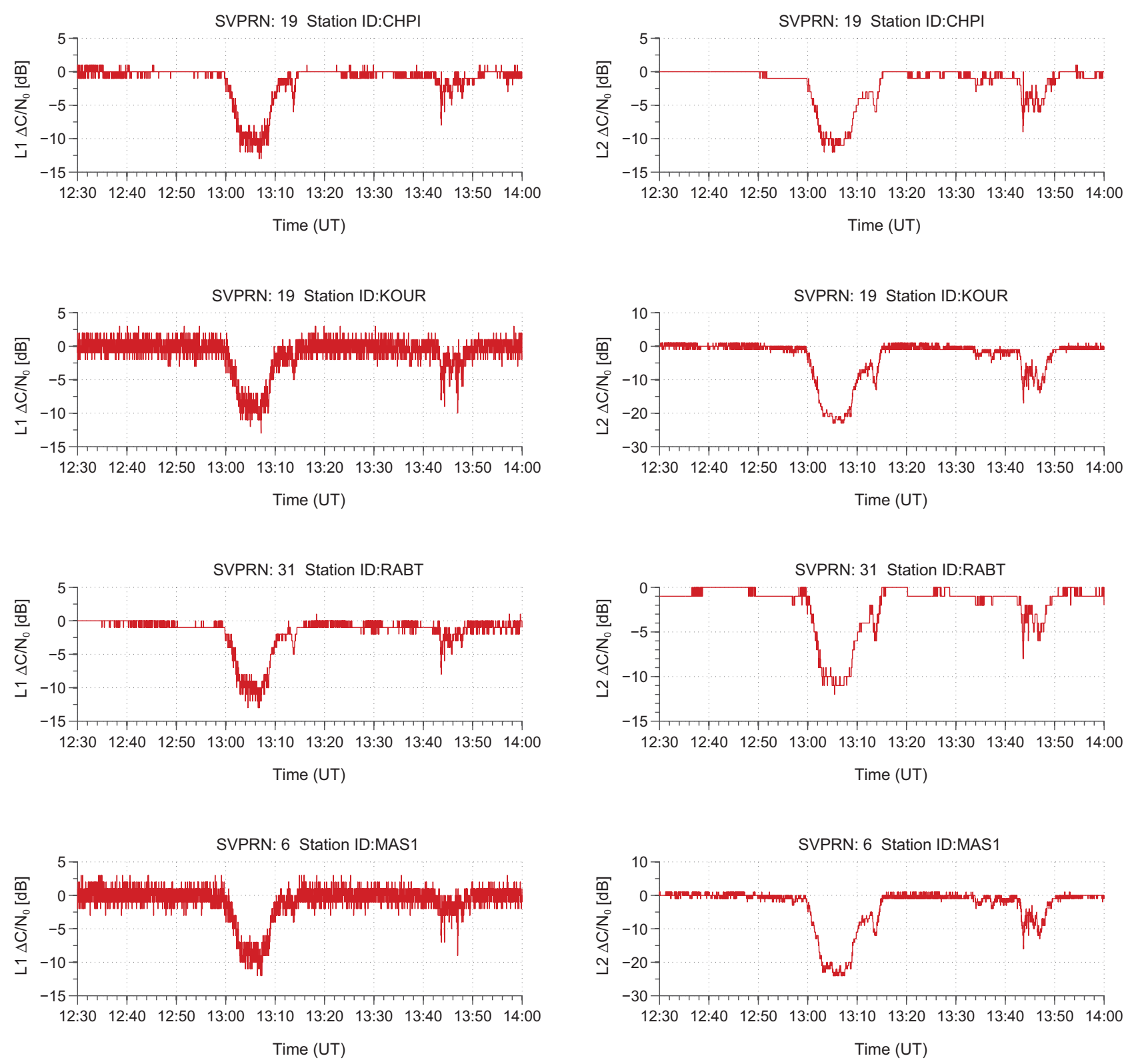

Fig. 4. GPS L1 and L2 $\Delta C / N_{0}$ during the September 24, 2011 solar radio burst.

emission of the three episodes are summarized in Table 1. It must be noted that no information about the polarization of the radio emission of the considered event is available, and that the recorded radio flux density is actually the sum of left-hand and right-hand circular polarization components and has to be considered as an upper limit to the amount of radio emission that can interfere with GPS receivers.

To analyze the impact of solar radio burst on GPS receiver performance, we obtained GPS L1 and L2 code-based pseudorange observables and $C / N_{0}$ values sampled at $1 \mathrm{~Hz}$ in the RINEX (Gurtner \& Estery 2007) format from a total number of 61 GPS receivers located in the sunlit hemisphere as shown in Figure 2. Out of the 61 receivers analyzed in this study, 35 GPS receivers belong to the International GNSS Service (IGS) network (Dow et al. 2009) and 26 receivers are part of the European Geostationary Navigation Overlay System (EGNOS) Ranging Integrity Monitoring Stations (RIMS) network (Brocard et al. 2000; GSA 2014). The EGNOS RIMS receivers collect measurements from GPS satellites and transmit the measurements to the Central Processing Facilities (CPF). The CPF computes the correction and integrity information based on the observed pseudorange measurements that is then broadcasted to the aviation users by means of geostationary satellites. The EGNOS RIMS receivers are involved in the provision of Safety of Life (SoL) services (GSA 2014); therefore, it is of utmost importance to assess their performance during the solar radio burst event. The details of the GPS receiver stations analyzed in this study are outlined in Table 2. It is worth mentioning that the EGNOS RIMS receivers information is classified, and therefore no receiver information was found in the RINEX file.

\section{Results and discussion}

\subsection{Degradation in $\mathrm{C} / \mathrm{N}_{0}$}

In this section we present maximum degradation in $C / N_{0}$ for both GPS L1 and L2 during each episode of the 
B. Muhammad et al.: Performance of GPS receivers during Sep. 24, 2011 solar radio burst event

Table 3. $\Delta C / N_{0}(\mathrm{~dB})$ at GPS receiver stations that experienced deep signal fades. $\theta_{\mathrm{SUN}}$ is the local solar incidence angle.

\begin{tabular}{|c|c|c|c|c|c|c|c|c|c|c|}
\hline \multirow[t]{2}{*}{ Station } & \multirow[t]{2}{*}{ Location } & \multicolumn{3}{|c|}{ Episode 1} & \multicolumn{3}{|c|}{ Episode 2} & \multicolumn{3}{|c|}{ Episode 3} \\
\hline & & $\begin{array}{l}\Delta C / N_{0} \\
\mathrm{~L} 1\end{array}$ & $\begin{array}{l}\Delta C / N_{0} \\
\mathrm{~L} 2\end{array}$ & $\theta_{\text {SUN }}$ & $\begin{array}{l}\Delta C / N_{0} \\
\mathrm{~L} 1\end{array}$ & $\begin{array}{l}\Delta C / N_{0} \\
\mathrm{~L} 2\end{array}$ & $\theta_{\text {SUN }}$ & $\begin{array}{l}\Delta C / N_{0} \\
\mathrm{~L} 1\end{array}$ & $\begin{array}{l}\Delta C / N_{0} \\
\mathrm{~L} 2\end{array}$ & $\theta_{\text {SUN }}$ \\
\hline CHPI & Sao Paulo, Brazil & 13 & 12 & $28.2^{\circ}$ & 6 & 6 & $29.9^{\circ}$ & 8 & 9 & $34.7^{\circ}$ \\
\hline KOUR & Kourou, French Guiana & 13 & 23 & $11.6^{\circ}$ & 5 & 13 & $14.1^{\circ}$ & 10 & 17 & $20.4^{\circ}$ \\
\hline RABT & Rabat, Morocco & 13 & 12 & $34.6^{\circ}$ & 5 & 6 & $34.4^{\circ}$ & 8 & 8 & $34.8^{\circ}$ \\
\hline MAS1 & $\begin{array}{l}\text { Maspalomas, Canary Islands, } \\
\text { Spain }\end{array}$ & 12 & 24 & $30.7^{\circ}$ & 4 & 12 & $29.7^{\circ}$ & 9 & 16 & $28.3^{\circ}$ \\
\hline WSRT & Westerbork, Netherlands & 11 & 21.75 & $53.5^{\circ}$ & 3 & 11 & $53.3^{\circ}$ & 5 & 14 & $53.4^{\circ}$ \\
\hline CRO1 & $\begin{array}{l}\text { Christiansted, Virgin Islands, } \\
\text { US }\end{array}$ & 11 & 10 & $22.5^{\circ}$ & 3 & 4 & $24.2^{\circ}$ & 5 & 6 & $29.0^{\circ}$ \\
\hline FFMJ & Frankfurt, Germany & 11 & 18 & $50.5^{\circ}$ & 3 & 7 & $50.5^{\circ}$ & 5 & 10 & $50.7^{\circ}$ \\
\hline EBRE & Ebro, Spain & 10 & 22 & $42.5^{\circ}$ & 3 & 11 & $41.9^{\circ}$ & 4 & 13 & $41.2^{\circ}$ \\
\hline TITZ & Titz, Germany & 10 & 18 & $51.6^{\circ}$ & 3 & 7 & $51.4^{\circ}$ & 6 & 10 & $51.5^{\circ}$ \\
\hline HUEG & Huegelheim, Germany & 9 & 15 & $48.3^{\circ}$ & 3 & 6 & $48.2^{\circ}$ & 4 & 7 & $48.4^{\circ}$ \\
\hline ACRA & Azores Islands, Portugal & 7 & N/A & $40.2^{\circ}$ & 4 & N/A & $39.6^{\circ}$ & 4 & N/A & $38.9^{\circ}$ \\
\hline ALBA & Aalborg, Denmark & 7 & N/A & $57.5^{\circ}$ & 4 & N/A & $57.4^{\circ}$ & 4 & N/A & $57.8^{\circ}$ \\
\hline ZURA & Zurich, Switzerland & 7 & N/A & $47.9^{\circ}$ & 4 & N/A & $48^{\circ}$ & 4 & N/A & $48.2^{\circ}$ \\
\hline ALYA & Alexandria, Egypt & 4 & N/A & $31.7^{\circ}$ & 0 & N/A & $32^{\circ}$ & 0 & N/A & $33^{\circ}$ \\
\hline DJAA & Djerba, Tunis & 4 & N/A & $36.7^{\circ}$ & 4 & N/A & $37.6^{\circ}$ & 4 & N/A & $40.7^{\circ}$ \\
\hline
\end{tabular}
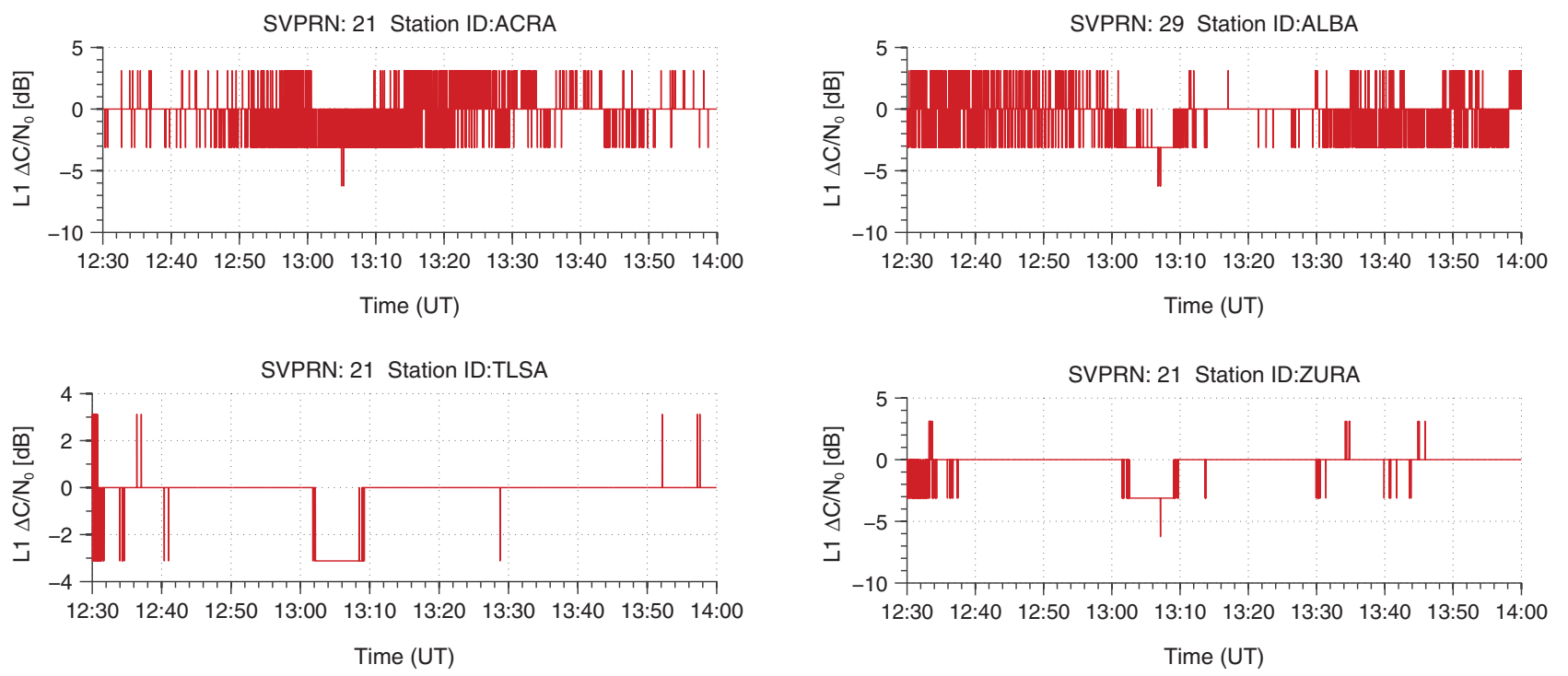

Fig. 5. L1 $\Delta C / N_{0}$ recorded at RIMS receivers during the September 24, 2011 solar radio burst. L2 $C / N_{0}$ values of EGNOS RIMS stations could not be found in RINEX files.

September 24, 2011 solar radio burst event. The degradation in $C / N_{0}$ is computed by subtracting the $C / N_{0}$ values measured on the event day from the $C / N_{0}$ values recorded on a quiet day. While analyzing the maximum reduction in $C / N_{0}$, we consider satellites at an elevation angle greater than $40^{\circ}$.

Figure 3 shows $C / N_{0}$ degradation on L1 and L2 at GPS receiver stations located in the sunlit hemisphere. During the episode-1, several GPS receivers including CHPI, KOUR, and RABT GPS stations experience maximum degradation of $13 \mathrm{~dB}$ on L1. MAS1 experienced $12 \mathrm{~dB}$ reduction, whereas $11 \mathrm{~dB}$ is recorded at WSRT, CRO1, and FFMJ. It can be observed that the degradation on L2 is high compared with L1 mainly due to the codeless/semi-codeless receiver operation in tracking L2. A maximum degradation of $24 \mathrm{~dB}$ is recorded on L2 at GPS receiver station MAS1. Other notable GPS receiver stations such as KOUR, EBRE, WSRT, and FFMJ experienced $C / N_{0}$ degradation of $23 \mathrm{~dB}, 22 \mathrm{~dB}, 21.75 \mathrm{~dB}$, and $18 \mathrm{~dB}$, respectively.

During the episode- 2 , the maximum degradation recorded on GPS L1 is $6 \mathrm{~dB}$ at CHPI, while the maximum reduction of $13 \mathrm{~dB}$ is experienced on GPS L2 at KOUR. GPS receiver stations such as MAS1 and EBRE recorded $12 \mathrm{~dB}$ and $11 \mathrm{~dB}$ respectively on GPS L2. The analysis of $C / N_{0}$ degradation during the solar radio burst episode- 3 shows the maximum reduction of $10 \mathrm{~dB}$ on $\mathrm{L} 1$ and $17 \mathrm{~dB}$ on $\mathrm{L} 2$ at GPS receiver station KOUR. Other notable stations include MAS1 where $C / N_{0} \mathrm{~L} 1$ degraded by $9 \mathrm{~dB}$ and $C / N_{0} \mathrm{~L} 2$ reduced by $16 \mathrm{~dB}$, WSRT experienced $C / N_{0} \mathrm{~L} 1$ reduction of $5 \mathrm{~dB}$ and $C / N_{0} \mathrm{~L} 2$ by $14 \mathrm{~dB}$. 

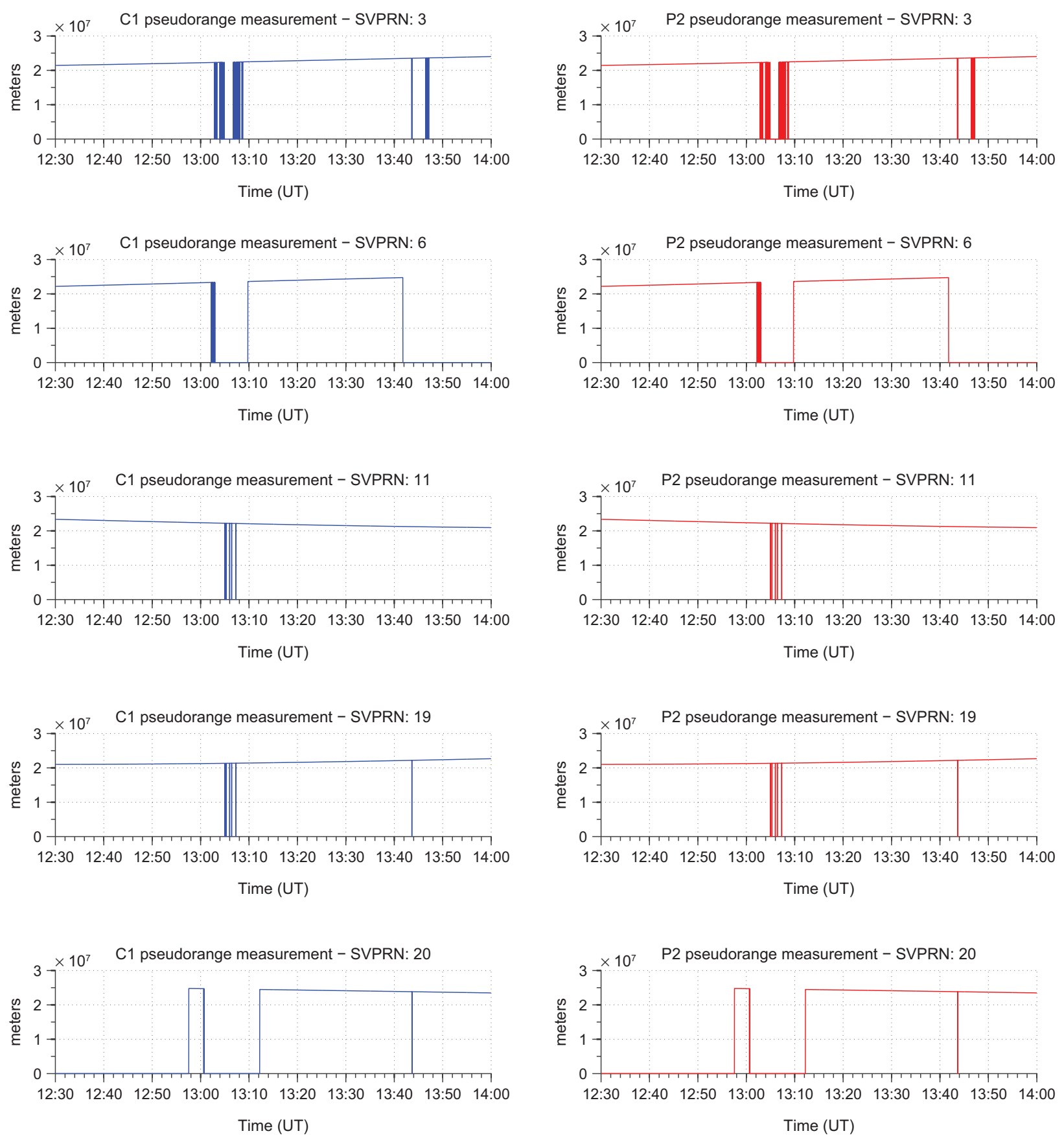

Fig. 6. $\mathrm{C} 1$ and $\mathrm{P} 2$ observations of visible satellites at CHPI during the September 24, 2011 solar radio burst.

Figure 4 shows the details of $C / N_{0}$ degradation at the GPS receiver stations that experienced relatively deep signal fades. It can be observed that the degradation is visible in all three episodes following the trend of solar radio burst activity as shown in Figure 1. GPS signal fading depends on local solar incidence angle and gain of GPS antenna at the solar incidence angle. Both the incidence angle and antenna gain contribute to the amount of solar radio noise entering the GPS antenna during the solar radio burst event. Table 3 lists GPS stations that experienced significant $C / N_{0}$ degradation. The GPS stations KOUR, CHPI, MASI, and RABT with local solar incidence angle $11.6^{\circ}, 28.2^{\circ}, 30.7^{\circ}$, and $34.6^{\circ}$ respectively experienced relatively deeper signal fades at both L1 and L2 during the solar radio burst event.
Figure 5 shows the details of GPS L1 $C / N_{0}$ degradation recorded at EGNOS RIMS receivers. It is worth mentioning that no GPS L2 $C / N_{0}$ information was found in the RINEX files obtained from EGNOS helpdesk. ${ }^{1}$ A maximum degradation of $7 \mathrm{~dB}$ on $\mathrm{L} 1$ is recorded at a number of EGNOS RIMS receivers that include ACRA, ALBA, and ZURA. It can be observed from Figure 5 that the $C / N_{0}$ degradation on L1 is less than the degradation recorded at IGS receiver stations. This could be due to the operation of Automatic Gain Control (AGC) circuitry that provides controlled signal amplitude at its output despite variation of

\footnotetext{
$\overline{{ }^{1} \mathrm{http} / / \text { egnos-user-support.essp-sas.eu/ }}$
} 
B. Muhammad et al.: Performance of GPS receivers during Sep. 24, 2011 solar radio burst event
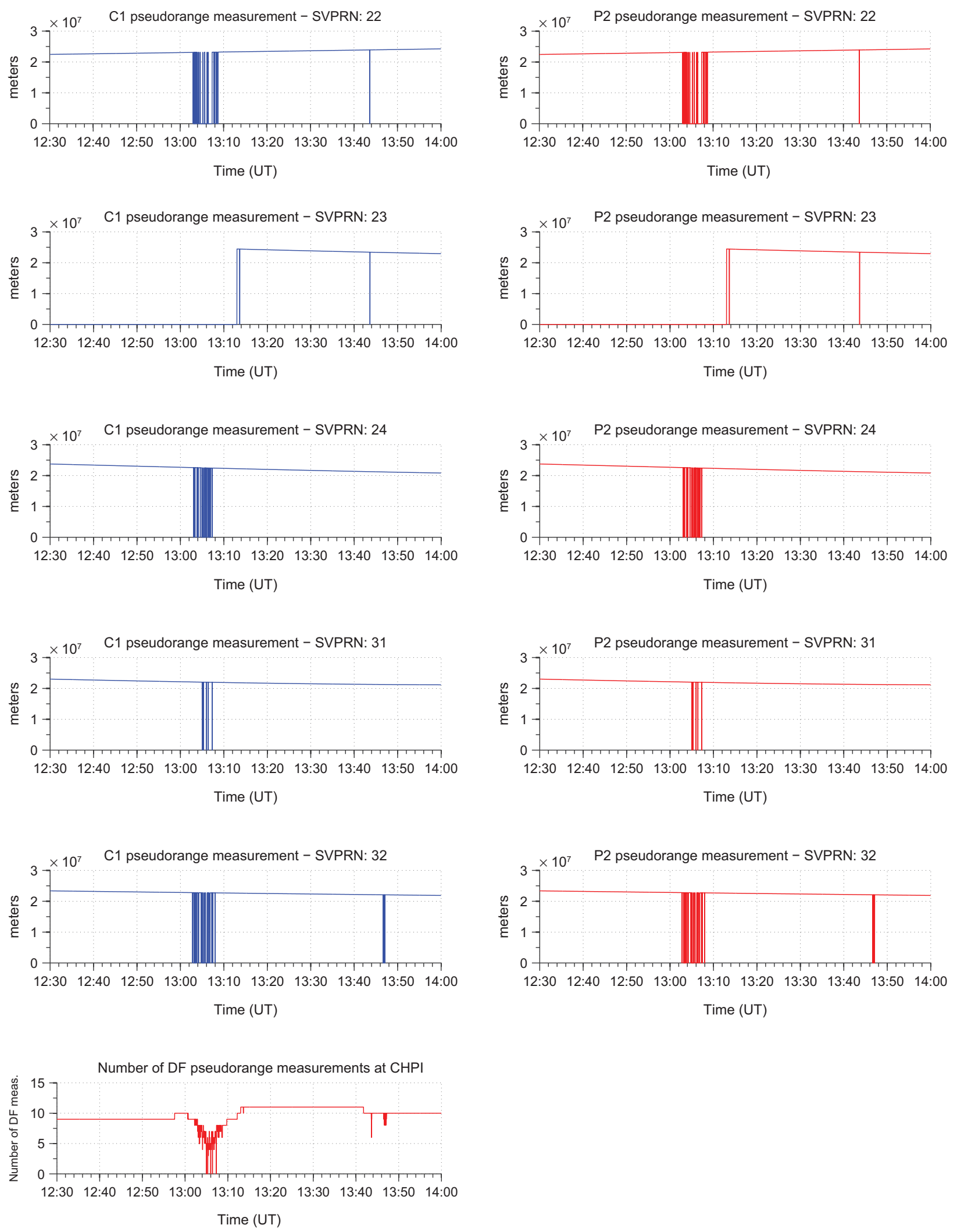

Fig. 6. Continued.

the amplitude in the input signal. Though AGC is present in every modern GNSS receiver, nevertheless, if the receiver is not specifically pre-designed to detect radio frequency interference, it will adapt its AGC gain as if there is only thermal Gaussian noise present (Bastide et al. 2003; Luo et al. 2003;

Akos 2012). Since RIMS receivers are used in monitoring the integrity of GNSS Signal in Space (SISE) to support civil aviation users through EGNOS, the receiver is pre-designed to lower the AGC gain in the presence of excessive noise and/or interference to comply with stringent performance requirement 
At 13:00:00
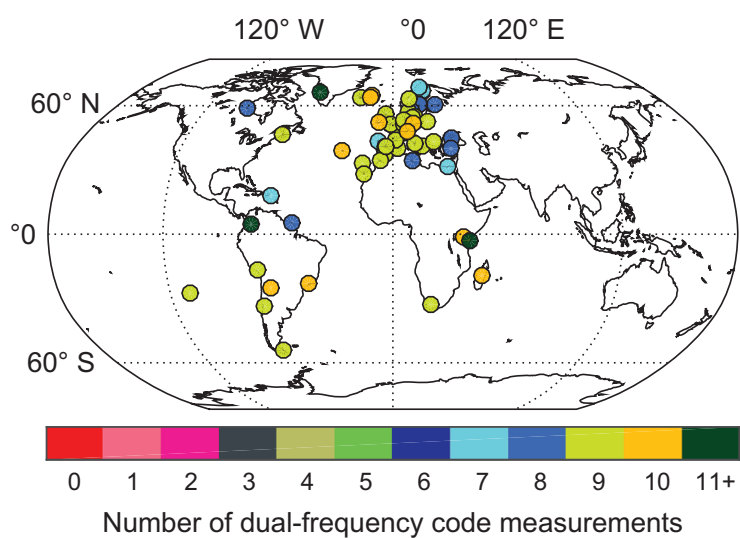

At 13:05:00

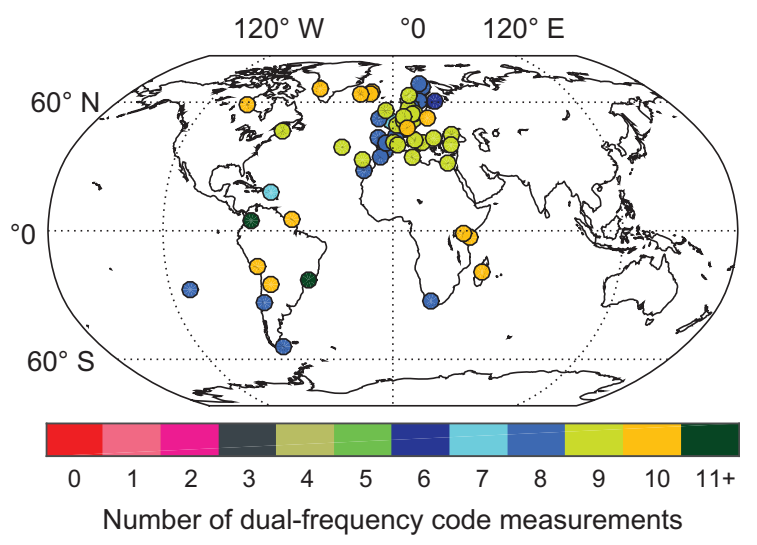

At 13:42:00

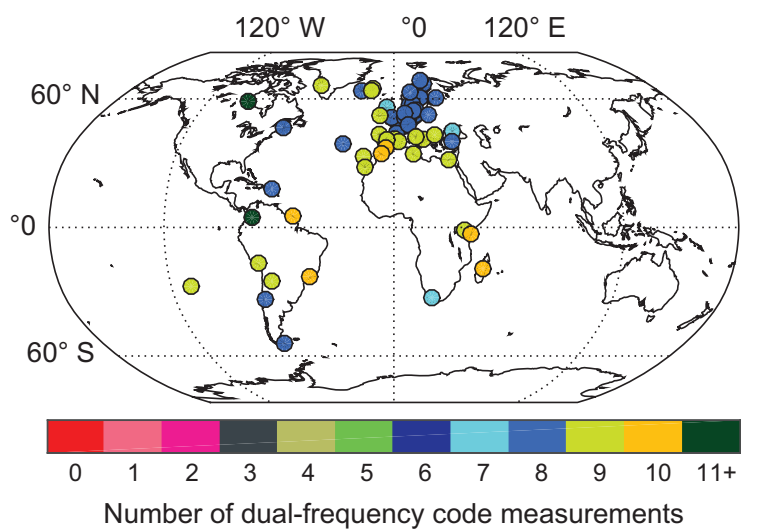

Episode 1

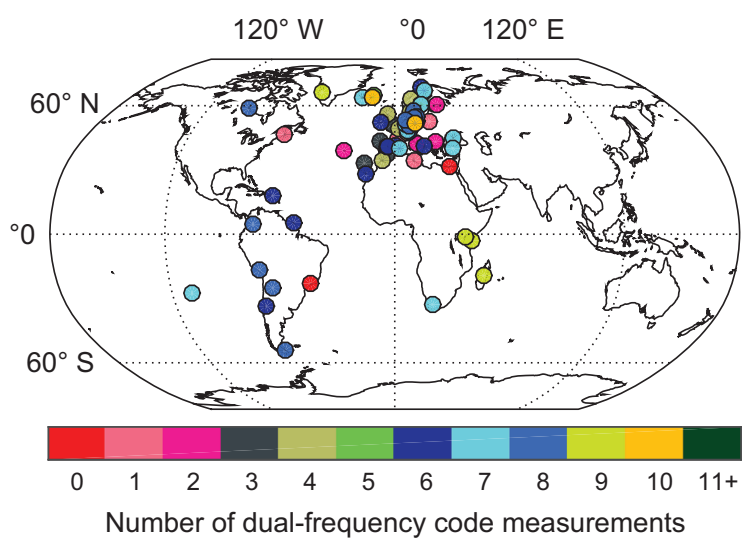

Episode 2

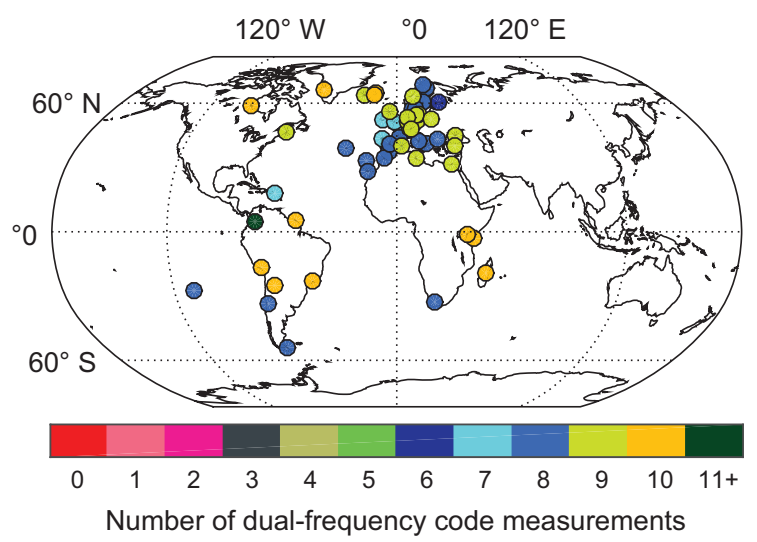

Episode 3

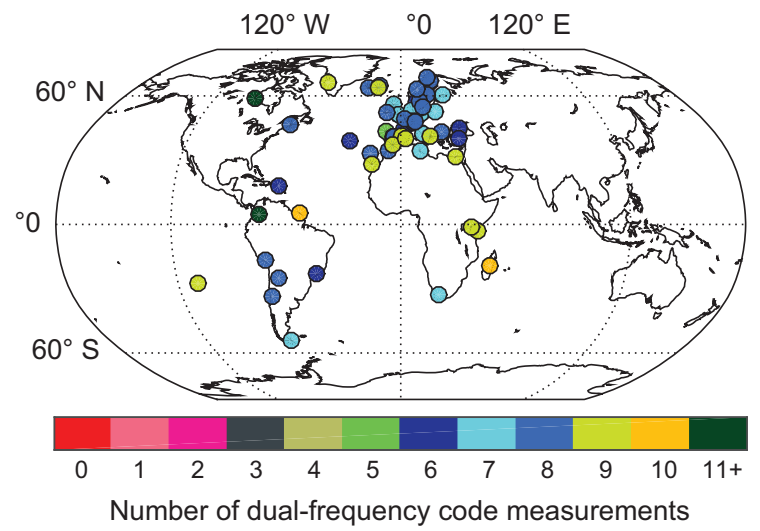

Fig. 7. Availability of minimum number of dual-frequency measurements for position estimation.

in detecting and/or mitigating the RFI (Neville \& Ashton 2003; ICAO 2006). The plots in Figure 5 indicate possible use of AGC in providing relatively controlled $C / N_{0}$ at the output of the GNSS receiver correlators compared with the IGS GPS receiver stations shown in Figure 4.

\subsection{Number of dual-frequency measurements}

In this section we present the availability of dual-frequency pseudorange measurements $\mathrm{C} 1$ and $\mathrm{P} 2$ for the estimation of position solution during the solar radio burst event. As shown in previous section, deep signal fades were experienced on both L1 and L2 frequencies. The degradation in $C / N_{0}$ causes the loss of lock of GPS signals, which ultimately reduces the number of dual-frequency pseudorange measurements for position estimation. Figure 6 shows $\mathrm{C} 1$ and P2 pseudorange measurements for all the tracked satellites during the solar radio burst at CHPI station. The discontinuity or drop indicates DLL loss of lock that can be observed at both $\mathrm{C} 1$ and $\mathrm{P} 2$ for all the tracked satellites during the solar radio burst event. During the peak solar radio burst event both $\mathrm{C} 1$ and $\mathrm{P} 2$ measurements are unavailable resulting in zero dual-frequency measurements for position estimation as shown in the last subfigure of Figure 6. 
B. Muhammad et al.: Performance of GPS receivers during Sep. 24, 2011 solar radio burst event
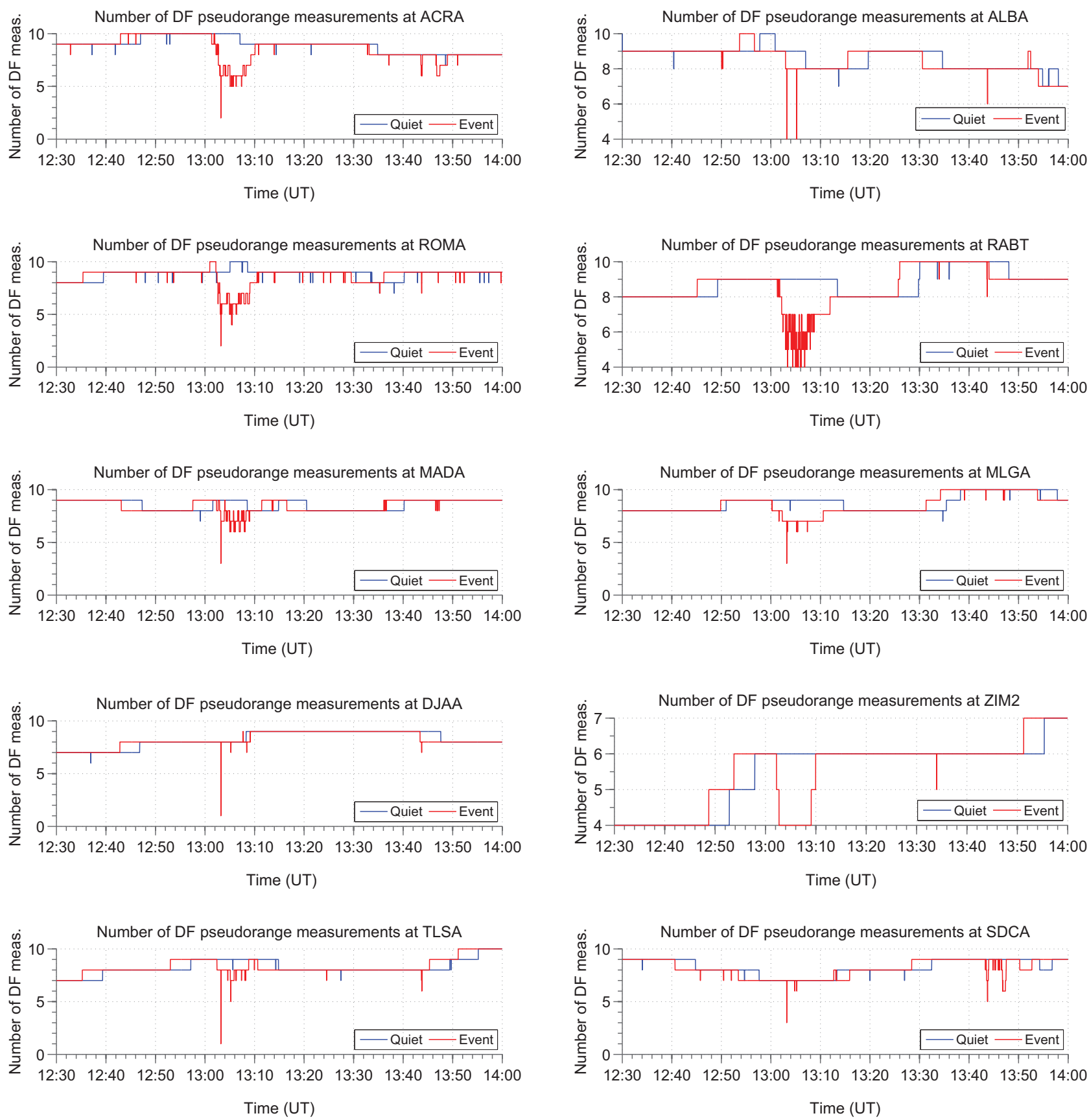

Fig. 8. Details of the availability of dual-frequency measurements at GPS a number of GPS receiver stations.

Figure 7 shows the number of available dual-frequency pseudorange measurements before and during the solar radio burst episodes for all the GPS stations. It can be observed that the available dual-frequency measurements vary from 6 to 12 before the peak solar radio burst, while the availability decreased during the solar radio burst episodes.

During the SRB episode-1, a total number of 55 out of 61 stations experienced loss of lock. The availability of dualfrequency pseudorange measurements was significantly reduced so that a total number of 15 stations experienced a dual-frequency pseudorange availability below 4, which are the minimum number of required measurements to compute a position fix.

During the solar radio burst episode-2, which is the least intense in terms of solar radio noise flux, the dual-frequency measurement availability is not significantly degraded compared with episode-1 as observed in Figure 7. Loss of lock is experienced at a total number of 13 GPS receiver stations out of 61 ; however, the maximum reduction of two dualfrequency measurements was recorded at the GPS receiver station PARA. During the episode-3, 30 stations out of 61 experienced loss of lock of GPS signals. The maximum reduction of four dual-frequency measurements was observed at GPS stations CHPI and SDCA.

Figure 8 shows the details of dual-frequency measurements availability on a quiet day (blue line) and solar radio burst event day (red line). It can be observed that the number of dual-frequency measurements abruptly dropped to four or below at many stations during episode- 1 of the solar radio burst event. Interestingly enough, 14 out of 15 stations, which 


\section{Episode 1}
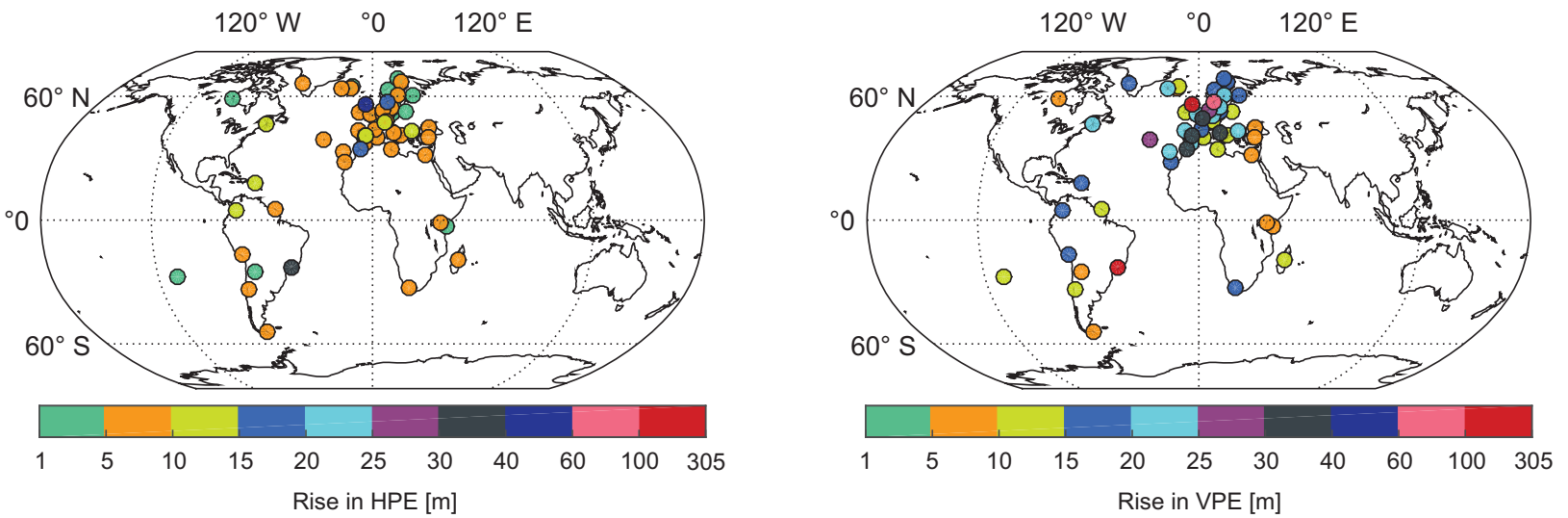

Episode 2
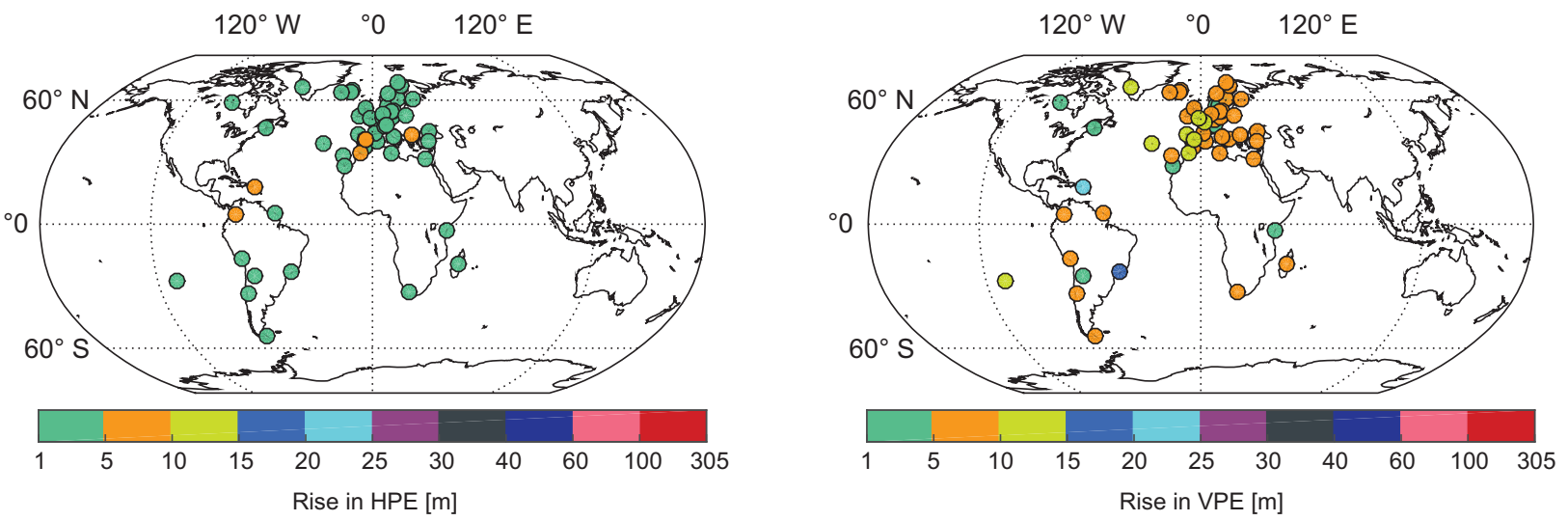

Episode 3
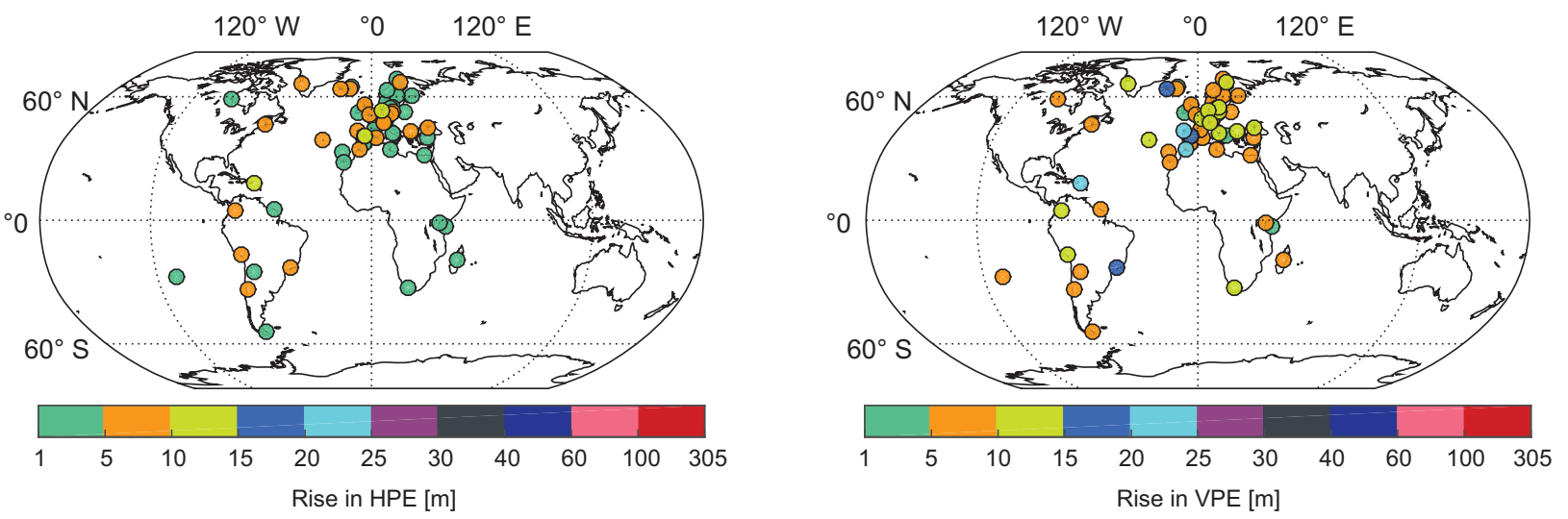

Fig. 9. Maximum rise in horizontal and vertical positioning errors during the solar radio burst episodes.

experienced less than 4 dual-frequency measurements, are the EGNOS RIMS receivers. The only station in the IGS network that experienced less than four dual-frequency measurement is the CHPI station.

Referring to Figure 8, the response of RIMS receivers to wideband solar RFI is different compared with that of IGS GPS stations such as CHPI, RABT, and ZIM2. It is worth mentioning that the EGNOS RIMS receivers are designed for meeting the stringent performance requirements of aviation (ICAO 2006) and would have similar receiver design characteristics, whereas the IGS receivers are mostly survey grade
GNSS receivers from variety of vendors. The similar receiver design characteristics of RIMS receivers are also evident from the identical response of all the EGNOS RIMS receivers to solar RFI that can be observed from Figure 8. For instance, the majority of the RIMS receiver stations experienced less than or exactly four dual-frequency measurements at 13:03:12 UTC given the fact that the peak solar radio burst occurred at 13:04:46 UTC as outlined in Table 1. The severe signal loss of lock experienced by the RIMS receivers before the peak solar radio burst could be due to the interference detection and/or mitigation mechanism deployed inside the 
B. Muhammad et al.: Performance of GPS receivers during Sep. 24, 2011 solar radio burst event
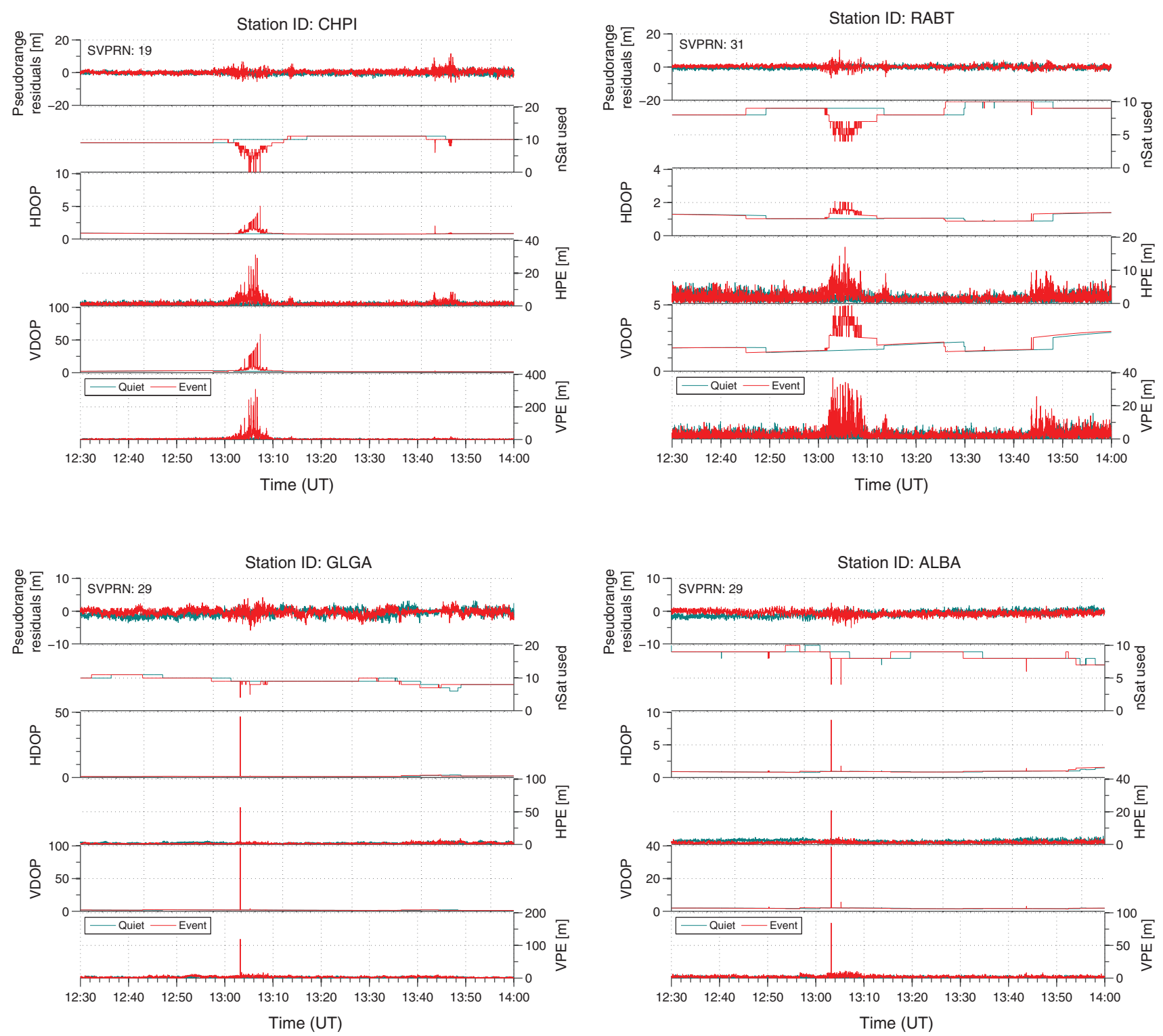

Fig. 10. Pseudorange residual error, number of dual-frequency satellite measurements (nSat) used for position estimation, HDOP, HPE, VDOP, and VPE during the September 24, 2011 solar radio burst event. Please, pay attention to both sides of the Y-axis of each subfigure, position of $Y$ axis is changing from left to right in successive subfigures.

receivers. On detecting the interference, the receiver might have dropped those measurements that were severely affected (e.g. below a certain threshold level), while at the same time responded to the interference by decreasing the AGC gain and/or varying the AGC dynamic range to minimize the impact of RFI on incoming signals. It can be observed that due to the early detection and interference mitigation to a certain degree the majority of the RIMS receivers experienced relatively minimal loss of lock when the solar radio activity intensified compared with the IGS receivers CHPI and RABT where the loss of lock gradually increased with the rise in solar radio interference. The detection of RFI and rapid adaptability to the excessive interference indicate the superior performance of RIMS receiver stations in coping the interference. Nevertheless, further analysis is needed to investigate the significant loss of lock on detecting the RFI in order to further improve robustness of RIMS receivers against the solar RFI.

\subsection{Positioning error}

The degradation in $C / N_{0}$ contributes to increase the error in estimated position solution by deteriorating the satellitereceiver geometry and/or causing significant code-tracking errors. In this section we quantify the rise in user positioning errors in horizontal and vertical dimensions during the solar radio burst event. We also present the HDOP/VDOP and pseudorange residual errors carrying the contribution of the receiver-code-tracking errors, which are the key indicators in analyzing the impact of solar radio burst event on the positioning performance.

GPS position solution is estimated at a rate of $1 \mathrm{~Hz}$ using dual-frequency code-based pseudorange observables obtained from 61 GPS receiver stations. The pseudorange observables are acquired for the September 23 and 24 and are sampled at $1 \mathrm{~Hz}$. The pseudorange observables are corrected for error 

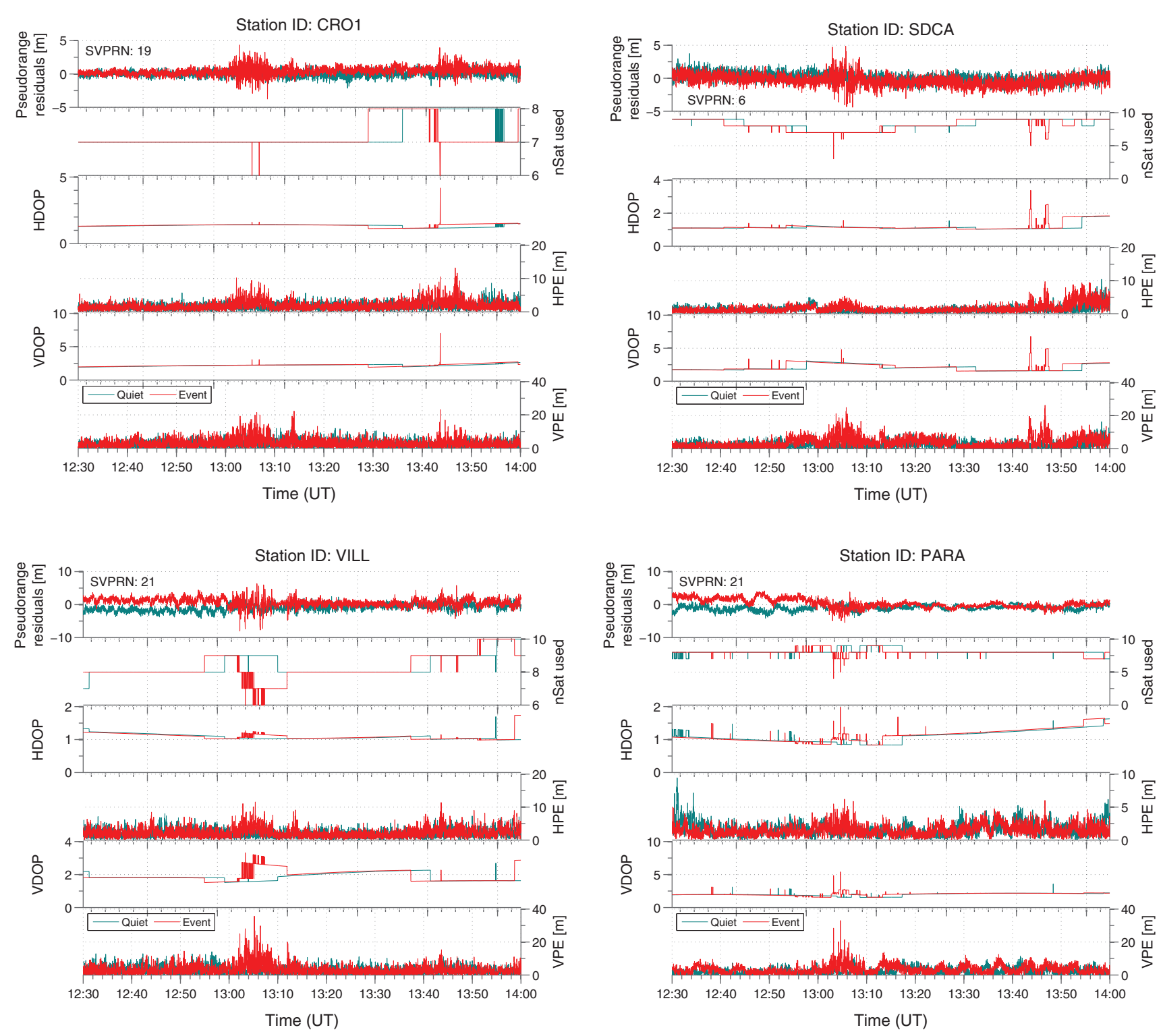

Fig. 10. Continued.

due to ionosphere using dual-frequency L1 and L2 code measurements (Conley et al. 2005), the error due to troposphere is corrected using Saastamoinen tropospheric model (Saastamoinen 1972), and the satellite ephemeris and clock errors are corrected using IGS final orbit and clock products. To further minimize the atmospheric and local multipath effect on the raw pseudorange measurements, an elevation mask of $10^{\circ}$ is considered in selecting the satellites for position estimation. The positioning errors in the final navigation solution are highly indicative of the receiver performance since all other pseudorange error are minimized.

Figure 9 shows the rise in Horizontal Positioning Error (HPE) and Vertical Positioning Error (VPE) during the September 24, 2011 solar radio burst event that spanned over three distinct episodes. The rise in error is computed by taking the difference of the positioning errors estimated on event day and the positioning errors recorded on a quiet day. As shown in the figure, during the episode-1, the rise in horizontal and vertical positioning errors is experienced across all the observed GPS receiver stations. The maximum estimated rise in HPE is $55 \mathrm{~m}$ at GLGA station. Other notable stations that

experienced rise in HPE of $30 \mathrm{~m}$ and $19 \mathrm{~m}$ are CHPI and ALBA respectively. The maximum rise in VPE of $303 \mathrm{~m}$ is recorded at CHPI, while $116 \mathrm{~m}$ is estimated at GLGA, $84 \mathrm{~m}$ at ALBA, $36 \mathrm{~m}$ at RABT, and $32 \mathrm{~m}$ at both PARA and VILL GPS stations.

During the episode- 2 of the solar radio burst event, the maximum rise of $8 \mathrm{~m}$ in HPE is estimated at VILL, whereas the maximum rise in VPE is estimated as $21 \mathrm{~m}$ at CRO1 and $17 \mathrm{~m}$ at CHPI.

During the solar radio burst episode-3, the maximum rise in HPE is $12 \mathrm{~m}$ as estimated at the GPS stations CRO1 and MAD2. The maximum rise of $24 \mathrm{~m}$ in VPE is experienced at RABT and SDCA stations, whereas $20 \mathrm{~m}$ rise in VPE is recorded at $\mathrm{CRO} 1$ and $18 \mathrm{~m}$ at MAD2.

Figure 10 shows the details of HDOP, VDOP, and pseudorange residual errors that contributed to increase the horizontal and vertical positioning errors during the solar radio burst event. It can be observed that the satellite-receiver geometry deteriorated due to loss of lock of GPS signals, which increased the HDOP and VDOP values causing large positioning errors in both horizontal and vertical dimensions. 
Furthermore, those signals that were locked by the receiver with degraded $C / N_{0}$ introduced code-tracking errors as evident in the pseudorange residual errors of one of the GPS satellites among a number of satellites used for the estimation of position solution. The code-tracking errors caused further degradation in the user positioning. The rise in positioning error due to degraded geometry and/or increased residual errors can be noticed in all the three solar radio burst episodes at the GPS receiver stations. At some receiver stations, the satellitereceiver geometry degraded significantly, and therefore, the HDOP and VDOP increased by a huge margin as shown in CHPI, ALBA, and GLGA stations. At CRO1 station during the episode-1 and episode-2, the increase in HDOP/VDOP is not significant but the rise in HPE/VPE is significant due to code-tracking errors visible in the pseudorange residual errors of SVPRN 19. This indicates that the code-tracking error due to drop in $C / N_{0}$ could cause significant degradation in the quality of the navigation position solution.

This article exclusively focused on the impact of solar radio burst on dual-frequency code-based positioning, and the impact on the performance of single-frequency positioning, which is considered as the most common method of GNSS positioning, will be studied in a separate article.

\section{Conclusion}

This work analyzes the impact of September 24, 2011 solar radio burst on the performance of GPS receivers located in the sunlit hemisphere. Deep signal fades were observed on both the GPS L1 and L2 during the solar radio burst event that spanned over three episodes of solar radio noise emission. The impact of deep signal fading due to solar radio frequency interference provoked signal loss of lock on both L1 and L2 such that 14 out of 26 EGNOS RIMS receiver stations experienced less than four dual-frequency measurements for a maximum duration of $1 \mathrm{~s}$. Furthermore, at multiple receiver stations, including both IGS and RIMS, the number of dualfrequency measurements dropped to exactly four. We observed that EGNOS RIMS receivers detected and managed the interference, to a certain degree, by controlling the $C / N_{0}$ during the peak solar radio burst period, thus minimizing the signal loss of lock. Nevertheless, the sudden loss of lock noticed at all the analyzed RIMS receivers due to detection of RFI demands detailed investigation to further improve the robustness of RIMS receiver against the solar RFI. It has to be remarked that the signature of the solar radio burst event was evident in the key factors contributing to the quality of the position solution estimate including the satellite-receiver geometry and pseudorange residual errors. The deteriorated satellite-receiver geometry and significant code-tracking errors during the solar radio burst event introduced large positioning errors in both the vertical and horizontal dimensions.

Acknowledgements. The editor thanks Sreeja Vadakke Veettil and an anonymous referee for their assistance in evaluating this paper.

\section{References}

Akos, D.M. Who's afraid of the spoofer? GPS/GNSS spoofing detection via automatic gain control (AGC). Navigation, 59 (4), 281-290, 2012.

Bastide, F., D. Akos, C. Macabiau, and B. Roturier. Automatic gain control (AGC) as an interference assessment tool, in ION GPS/GNSS 2003, 16th International Technical Meeting of the
Satellite Division of the Institute of Navigation, Portland, OR, 2042-2053, 2003.

Brocard, D., T. Maier, and C. Busquet. EGNOS Ranging and Integrity Monitoring Stations (RIMS), in GNSS 2000 Conference, Edinburgh, Scotland, UK, 2000.

Carrano, C.S., C.T. Bridgwood, and K.M. Groves. Impacts of the December 2006 solar radio bursts on the performance of GPS. Radio Sci., 44 (1), RS0A25, 2009, DOI: 10.1029/2008RS004071.

Cerruti, A.P., P.M. Kintner, D.E. Gary, L.J. Lanzerotti, E.R. de Paula, and H.B. Vo. Observed solar radio burst effects on GPS/ Wide Area Augmentation System carrier-to-noise ratio. Space Weather, 4 (10), S10006, 2006, DOI: 10.1029/2006SW000254.

Chen, Z., Y. Gao, and Z. Liu. Evaluation of solar radio bursts' effect on GPS receiver signal tracking within International GPS Service network. Radio Sci., 40 (3), RS3012, 2005, DOI: $10.1029 / 2004 \mathrm{RS} 003066$.

Conley, R., R. Cosentino, C. Hegarty, E. Kaplan, J. Leva, M.U. de Haag, and K. Van Dyke. Performance of Stand-Alone GPS. In: E.D. Kaplan, and C.J. Hegarty, Editors. Understanding GPS: Principles and Applications, chap. 7, 2nd edn., Artech House, 301-378, 2005.

Dow, J.M., R. Neilan, and C. Rizos. The international GNSS service in a changing landscape of global navigation satellite systems. J. Geod., 83 (3-4), 191-198, 2009.

GPS ICD. Navstar GPS Space Segment/Navigation User Interfaces. Interface Specification, 2012.

GSA. EGNOS safety of life service definition document, Tech. Report, European GNSS Agency, 2014.

Gurtner, W., and L. Estery. RINEX-The Receiver Independent Exchange Format-Version 3.00, Astronomical Institute, University of Bern and UNAVCO, Boulder, Colorado, 2007.

Herrera, A.M., H.F. Suhandri, E. Realini, M. Reguzzoni, and M.C. de Lacy. goGPS: open-source MATLAB software. GPS Solutions, 1-9, 2015.

ICAO. International Standards and Recommended Practices, Annex 10 to the Convention on International Civil Aviation. Radio Navigation Aids, vol. 1, 2006.

Kennewell, J.A. Solar radio interference to satellite downlinks, International Conference on Antennas and Propagation (ICAP 89), 1, 334-339, 1989.

Klobuchar, J.A., J.M. Kunches, and A. Van Dierendonck. Eye on the ionosphere: potential solar radio burst effects on GPS signal to noise. GPS Solutions, 3 (2), 69-71, 1999.

Kouba, J. A guide to using International GNSS Service (IGS) products. Unpublished, available electronically at http:// igscb.jpl.nasa.gov/igscb/resource/pubs/UsingIGSProductsVer21.pdf, 2009.

Langley, R.B. Dilution of precision. GPS World, 10 (5), 52-59, 1999.

Luo, M., G. Xie, D. Akos, S. Pullen, and P. Enge. Radio frequency interference validation testing for LAAS using the Stanford Integrity Monitor Testbed, in Proceedings of the Institute of Navigation National Technical Meeting, Anaheim, CA, 2003.

Marreiros, J. Kinematic GNSS precise point positioning-application to marine platforms, Ph.D. thesis, 2012.

Neville, C., and K. Ashton. Interference protection for EGNOS RIMS, in Proceedings of the 16th International Technical Meeting of the Satellite Division of the Institute of Navigation (ION GPS/GNSS), 2003.

Parkinson, B.W. GPS error analysis. In: B.W. Parkinson, and J.J. Spilker Jr., Editors. Global Positioning System: Theory and applications, vol. 1, chap. 11, American Institute of Aeronautics and Astronautics, Washington, DC, 469-483, 1996.

Saastamoinen, J. Atmospheric correction for the troposphere and stratosphere in radio ranging satellites. The use of artificial satellites for geodesy, 247-251, 1972.

Spilker, J.J. GPS signal structure and theoretical performance. In: B.W. Parkinson, and J.J. Spilker Jr., Editors. Global Positioning System: Theory and applications, vol. 1, chap. 3, American 
Institute of Aeronautics and Astronautics, Washington, DC, 57-119, 1996.

Sreeja, V., M. Aquino, and K. Jong. Impact of the 24 September 2011 solar radio burst on the performance of GNSS receivers. Space Weather, 11 (5), 306-312, 2013.

Sreeja, V., M. Aquino, K. Jong, and H. Visser. Effect of the 24 September 2011 solar radio burst on precise point positioning service. Space Weather, 12 (3), 143-147, 2014.
Ward, P.W., J.W. Betz, and C.J. Hegarty. GPS satellite signal characteristics. In: E.D. Kaplan, and C.J. Hegarty, Editors. Understanding GPS: Principles and Applications, chap. 4, 2nd edn., Artech House, 113-154, 2005a.

Ward, P.W., J.W. Betz, and C.J. Hegarty. Satellite signal acquisition, tracking, data demodulation. In: E.D. Kaplan, and C.J. Hegarty, Editors. Understanding GPS: Principles and Applications, chap. 5, 2nd edn., Artech House, 194-199, 2005b.

Cite this article as: Muhammad B, Alberti V, Marassi A, Cianca E \& Messerotti M. Performance assessment of GPS receivers during the September 24, 2011 solar radio burst event. J. Space Weather Space Clim., 5, A32, 2015, DOI: 10.1051/swsc/2015034. 